\title{
Consciousness and its relation with subconscious mind: The mystery probed
}

\author{
Author: \\ Krishanu Kumar Das \\ Affiliation of the Author: \\ Department of Medicine, HLG Memorial Hospital, Asansol, India
}

E-mail Address:

dr.krisdas@yandex.com 


\section{Abstract}

What is the nature of consciousness and how it is related to subconscious mind? What drives our conscious and subconscious mind? Is your mind yours? If I tell you to read the telephone directory from cover to cover without missing a single word - probably you will get some idea behind what consciousness is. If we deeply think our consciousness is equivalent to molecular tendency. It is equivalent to sodium's affinity to react with water to make a stable compound. There is no need to import divine attribute upon consciousness. But can we say 'sodium is conscious'? - not in the way by which we feel our very subjective consciousness. Then why our consciousness evolved? It evolved to guide an array of complex molecular reactions that accidentally trapped into a cycle within our earth's microcosm. Consciousness is a part of this cycle, though not always essential in this cycle. Any organism that can feel, we can say it is conscious, though it may not experience conscious intellectual workings. Human consciousness is the highest developed form of the feelings that can feel sensory perceptions as well as intellectual workings and others. In this article we have also defined our subconscious mind and how it differs from conscious mind. There are a good number of questions regarding our subconscious mind. Is it more powerful than our conscious mind? Does the drive that works for conscious mind work for subconscious too? We all experience somehow the presence of our subconscious mind, but where in the structures of brain it resides? Can subconscious be autoactivated and act on its own? Can subconscious create its own goal? Or can its activities be primed for a goal? In this treatise, we reviewed different literatures and tried to give answers to these questions to demystify the nature and realm of activities of our conscious and subconscious mind.

Keywords: Consciousness, Subconscious, Emotions, Motivation, Emotional Adaptation, Subliminal Perception, Priming. 


\section{Introduction:}

The consciousness is our subjective experience of the world and the mind. Old Vedic philosophy divided our living existence into consciousness (atman), mind, and body. Mind and body are perishable, whereas consciousness is imperishable. Consciousness pervades the whole universe, and when it illuminates mind and body, we get our subjective experience of our consciousness. This philosophy is trichotomous in nature, which separates consciousness from the mind which is composed of our individual memories and experiences. Later on, medieval philosophers, pioneered by Rene Descartes, propagated the theory of mind-body dualism. According to Descartes, the body is made up of material things, but mind is another separate immaterial entity. And when they meet in a particular structure within our brain, our very own consciousness engenders. Today, most of the scientists and scholars neither believe in dualism, nor do they think that consciousness has its any immaterial origin. However, if consciousness originates out of physical properties of the brain, it is not the only feature of our mind. There are state of the mind that lies below the level of consciousness. This concept of subconscious mind or unconscious mind described in Shrimad Bhagavad Gita (part of epic Mahabharata), where Lord Sri Krishna explains to princess Arjuna how to control 'Karma' (our conscious thoughts, speech, behaviors, and actions). Sri Krishna describes there is an underlying state of the mind which is composed of individual traits, likes and dislikes - from where our conscious desires, instincts, arise. He called this level of mind 'Prakriti' (chapter 3, verse 33 \& 34) [Basant \& Das, 1905; Sarvapriyananda, 2012]. But what Sri Krishna meant is actually the mental nature of a person, not ideally subconscious activity. At the close of the $19^{\text {th }}$ century, lots of interests were shown upon subconscious or unconscious mind. Pierre Janet used the word 'subconscients' (French synonym of 'subconscious') in his article to designate the state of mind enveloped under our consciousness [Janet, 1889]. Swami Vivekananda ${ }^{1}$ divided human mind into three planes - 'subconscious', 'conscious', and 'superconscious'. 'Superconscious' is the higher introspective state of the mind that can control its hammering emotional desires and can detach them from mind at its will [Vivekananda, 1896]. Sigmund Freud, at the beginning of his career, used the term 'subconscious' to mean activities of mind that occur below the level of our conscious mind. But later he preferred to use the term 'unconscious' for the same purpose and abandoned the usage of the former word. In his book 'The Interpretation of Dreams', Freud advanced 'Topographic theory of mind', dividing the mind into three domains - 'conscious', 'preconscious', and 'unconscious', making 'preconscious' as a subterranean layer interposed between the two, which has access to both of them. According to him, the contents of the unconscious can reach the conscious only by passing through the preconscious [Freud, 1900]. In psychology, the term 'subconscious' is much less used in preference of the term 'unconscious'. The term rather is much used in contemporary self-help literature, which adds a lot of myths to it rather than an approach to scientific understanding.

\footnotetext{
${ }^{1}$ \# Swami Vivekananda was a spiritual leader, not a personage from the scientific world. Yet, parts of his works on consciousness are very relevant to science.
} 
Here in this article, we will differentiate the mind in three domains 'conscious', 'subconscious' and 'unconscious' completely from a different perspective.

\section{The Conscious Mind}

All of our activities of the mind can be divided into three domains, (1) Conscious (2) Subconscious, and (3) Unconscious.

First, we will come to our conscious part of the mind. Mind's conscious activities are those which occur with awareness of the organism. In general sense, what we feel to be our 'mind', comes under this domain. Our thinking, emotional affections, volitional activities are all part of our conscious mind. Now, before we go to further discussion, we will describe the four houses of mind.

\section{Four Houses of Mind}

The activities of the mind are centered in four major houses in our brain. Though, these houses are assigned to perform in their respective areas of work, they are interconnected with each other through a number of joining corridors or neural pathways. That means activity of one house can influence others and vice versa. So, their actions are inter-related [Das, 2016].

These four houses are:

(1) House of Memory, (2) House of Intelligence, (3) House of Emotions, and

(4) House of Physical Activities. ${ }^{2}$

All of these houses are again sub-partitioned into three faculties:

(1) Reflexive Faculty, (2) Short-term Faculty, and (3) Long-term Faculty.

Though the activities of these houses can be conducted in our conscious realm of the mind, they can be run subconsciously too. And they can regulate or influence the centers responsible for brain's unconscious autonomic activities also.

Controlling cabins of all of these houses are situated in different areas of the brain (Fig.1). The house of intelligence is controlled by the prefrontal cortex situated in the frontal area of the cerebral cortex of our brain. The house of physical activity is controlled by the motor and premotor cortex of our brain. The house of emotion is maintained by the limbic system of the brain, which is composed of limbic cortex, a rim of cortical tissue around the hilus of the adjoining cerebral hemispheres, and a number of associated deep structures - the hypothalamus, the amygdala, the anterior nuclei of thalamus, the para-olfactory areas, the fornix, the hippocampus, the nucleus accumbens, the cingulate gyrus, the mammillary bodies, the orbitofrontal cortex, and the septal nuclei (Fig.1b). And the house of memory is run by

\footnotetext{
2 \# The difference between a computer and a human mind is that in computer the 'house of emotion' is absent [Das, 2016]. Computer or robot works through some input algorithms, driven by some introduced instructions. Human mind builds algorithms through experiences and is driven by its emotional impulses.
} 
different association areas in different parts of the brain. Sensory or perceptual memories are stored in the respective sensory association areas for the senses. Like, visual memories are stored in visual association area adjacent to primary visual cortex in the cerebrum. Auditory

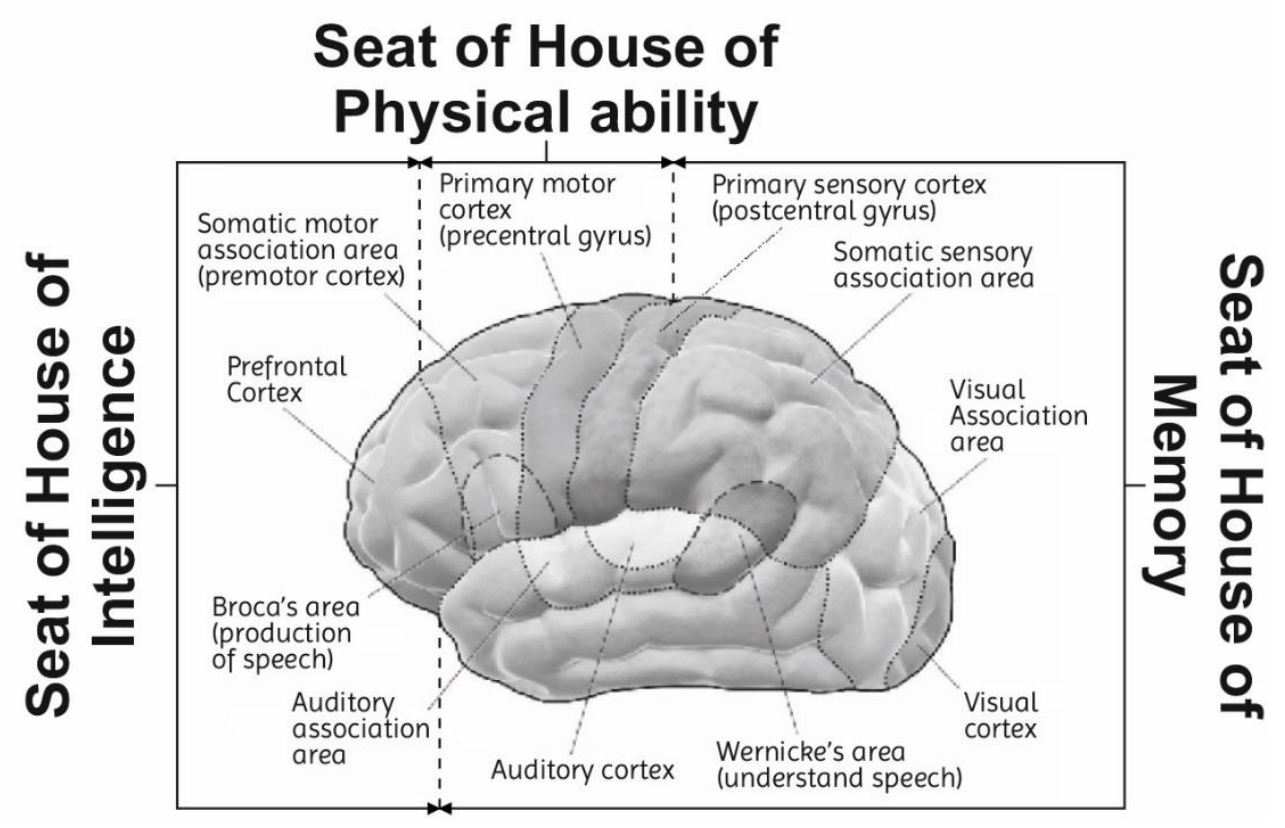

(a): Houses of 'Memory', 'Intelligence', and 'Physical Activities'.

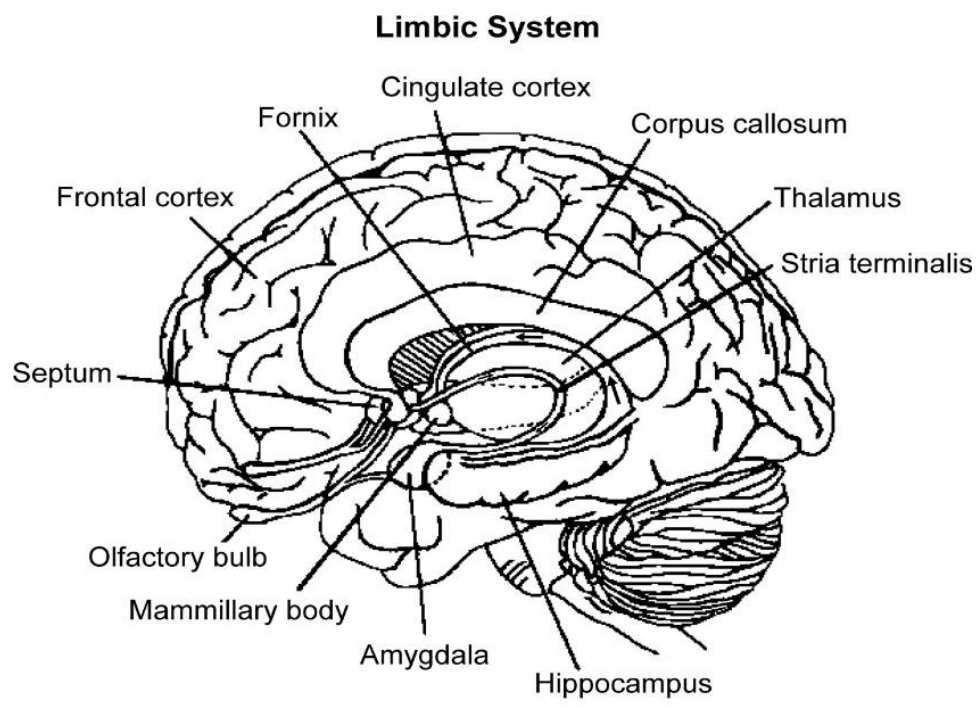

Basic ganglia removed

(b): House of 'Emotions'.

Fig. 1: Location of Four Major Houses (a \& b)

(Image in ' $a$ ' adapted from Blausen medical gallery) 
memories are stored in auditory association area adjacent to primary auditory cortex; and so others (Fig.1a). Besides sensory or perceptual information, memories of intellectual processes that we've already undergone, and memories of past emotional experiences are also stocked in frontal association area and association area in limbic cortex respectively.

Of these four houses, the house of emotions sets our goals, the house of memory and the house of intelligence are our means, and the house of physical activities effectuate our output actions. Input is done by different sensory perceptions that can affect the houses or can be stored as memories in the house of memory for variable times.

Now, when sensory perceptions as well as any activities of any of these houses give us a feeling, we become aware of it, and we experience our consciousness. Consciousness is like a hopping monkey, hopping from one branch of tree to another branch, looking around or doing something, then again jumping to another branch of the same tree or another tree - as our conscious mind do - sometimes recalling a memory (house of memory), sometimes calculating a bill (house of intelligence), sometimes threading a needle (house of physical activity). How perceptual information, intellectual workings, emotional affections give us feelings - that we call 'the hard problem of consciousness'.

So, consciousness is a kind of feeling. Consciousness is a subjective experience. Though writing this word may provoke hatred, the truth is that spiritualists may invite us into their illusory world, but our consciousness is just the developed form of the feeling of pain that first felt by a primitive organism. We unnecessarily impart nobility and divinity upon our consciousness and make the things more complicated. The pain first felt by an organism to withdraw from a noxious stimulus is no different from the pressure of emotion 'curiosity' by which I am writing this article. Are you yours truly? The answer is possibly 'not'. If it were so, you would not have suffered from depression, despair or emotional blankness. But being the most intellectual animal on earth, we can manipulate those within a boundary if we have proper knowledge. But thinking of going beyond that boundary is just a denial and an illusion.

Consciousness is not the sole property of human. Any organism that can feel is conscious. But the quality of consciousness varies. If you have a pet dog at home, watch him. He knows the time of return of his master or other beloved ones. At the slightest knock in the door, he will jump to the door with all preparedness of greeting. How can you say he has no consciousness? But, of course, his consciousness is not as fluent and as sophisticated as ours. He, obviously, does not think about when the universe began. Learning of language and its verbal expression has made transference of knowledge easier as well as made our conscious thinking sophisticated. Through this transference, we get knowledge gathered in thousands of years. Without having the knowledge of laws of gravity, theory of relativity, and others, maybe we also would not think of when the universe began. Animals are deprived of this opportunity. The required intellectual level to learn and understand a language is not possessed by the animals. Just like for running a software program, a computer needs required hardware, RAM and other upgradations. Again, language has not been as sophisticated as today's languages at once. It took thousands of years. Primitive men depended on simple verbal sounds without any 
grammar - just 'this verbal sound means that'. Transference of knowledge has also been accomplished through cave paintings, engravings, etc.

Pierson and Trout hypothesized that consciousness evolved to make volitional movements possible [Pierson \& Trout, 2017].

Can you think of an organism that can feel or have consciousness, but does not move? probably not.

It is true that our volitional movements of the house of physical activities is the output device of our mind. Without the output device, what is the role of the house of memory and the house of intelligence, if they cannot effectuate their processed products? And how the house of emotions can serve its goals through the means of those both houses?

But many organisms can move, yet don't have any feelings, i.e., consciousness. Many plants, bacteria, unicellular and multicellular lower animals show movements, but they don't have any feelings or consciousness. So, all organisms that have consciousness can move, but not all organisms that move, have consciousness.

Many says, 'stream of consciousness', as if it is flowing from birth to death. But it is not so. Consciousness is broken in sleep, in anesthesia. Yet you don't feel a different person after sleep or anesthesia because stored memories remain the same. Time sequence in the stored memories is maintained by the overlapping, shadowing, comparison with associated memories, just as we get the perception of depth in monocular vision, and also by the faintness of the memories. But in different types of physiological or pathological amnesia where parts or whole of memories are deleted, the person would feel a different person. Again, the stream of thinking can be freezed. If you practice meditation ('Dhyana' in Sanskrit), you should learn to freeze your thinking. Indian yogis could freeze their thinking for a prolonged time. The marvel is when you freeze your thinking, the driving forces cannot drive you any more to adjust your thoughts and behaviour according to their demands. Instead, the driving forces themselves would be adjusted. Not to be elaborated, here by 'driving forces', I mean 'emotional driving forces'. And that is the essence of meditation. Through the practice of meditation, you will get mental stability and peace, but you will have to compromise with your emotional exuberance. Your mind is not completely yours. It is like a wild horse confined in your brain. You can harness it, or can give it liberty for roaming wild. But what you cannot do is that you cannot change its identity or change its natural trends. Again, this insight had been achieved by the Indian yogis through their high level of intelligence. Other creatures do not possess this insight, not even all humans do.

The difference between a computer or AI or a robot and a human mind is that they all have house of memory, house of intelligence, and house of physical activities. But computers or AI or robots do not possess the house of emotions. For that, they do not have any self-desires or self-goals. But suppose we established 'the house of emotions' within them, so that their activities would either be guided automatically towards specific target/targets (remember the movie 'Terminator'), or be guided by something just like our continuously leaking house of emotions (explained later) so that continuous drives can be maintained. Even in that case, can 
they have consciousness as we feel our consciousness or inner world? That is a very difficult question. However, by somehow, we may create memorious, intellectual, or physical feelings artificially, but to create emotional feelings artificially just like ours would be very hard by humans. These emotional feelings make our conscious inner world, our life so vibrant, so colorful. When we think how deep is Mariana Trench, there acts behind our great passion of 'curiosity'. Without it, it would have been just an inquiry of information out of thousands.

There are also some other centers in our brain save these four houses, like the area controlling sleep and wakefulness, or the area controlling mood; which have to be regarded as the accessory or regulating parts of our conscious mind. The details of their mode of activities have been described elsewhere [Das, 2016, 2017, 2018].

\section{The Subconscious Mind}

Now, what is our subconscious? Our subconscious though remains predominantly beyond the reach of our conscious mind, many of our mind's activities are processed in subconscious. And we, sometimes, get projection of it through intuition or sudden retrieval of a memory; or through dreams into our consciousness. We become tired to solve some problem, suddenly solution comes to our mind in some relaxed moment or when away from thinking about it. It means that subconscious was working on it all the time. So, it functions as a backstage to our conscious mind where many of our conscious activities are rehearsed, evaluated, processed and finalized for actions like - storage in long-term memory, or projection into our consciousness through different ways. So, we may call it sub-conscious mind.

Difference between our conscious and subconscious mind is our subconscious activities are dependent on learned knowledge or embedded memories - informational memories, intellectual memories, emotional memories - all types of memories. Subconscious can act with wide knowledge that has been gathered consciously. But subconscious cannot perceive anything itself. Subconscious cannot watch, hear, touch, taste, smell, and so on. It can only work with the recapitulated memories of these feelings. When one is driving a car while thinking about some other things, the visual imageries of the streets become at minimum conscious level, or when one is reading an absorbing book, the visual perception of the words of the book become almost negligibly conscious. But that does not mean they are subconscious activities. One may mistake by regarding these functions as subconscious activities. Subconscious can perform the act of driving by our already memorized algorithms of how to drive a car, can stop at red light automatically, but if any new unexpected novel situation comes afront that has not been faced before, subconscious will fail to take any action in that situation. Our conscious and subconscious mind work very closely, hand-in-hand. Our subconscious activities are our brain's automatic activities dependent on pre-embedded knowledge, and do not give any feelings to us; whereas, our conscious activities give us always particular feelings.

Our conscious activities of the mind, as already described, are conducted by the different parts of our brain. So, one may wonder - 'Where then resides our subconscious?'. To make it easier, it has to be said that not the activities of all the houses always come into consciousness at the same time. 
Some of the activities of some houses come into consciousness, while others are not. But that does not mean that the activities of other houses of our brain are completely shut off at that particular moment. They all work, but are not focused at the same time into our consciousness. So, when one was enjoying some movie, may be his house of intelligence was working on some of his worries that he had experienced earlier. After the work-up is complete, the resolution suddenly came up in his mind. He got surprised as he was not attentively thinking on that problem with conscious effort.

So, our subconscious is nothing but the latent activities of all four houses of the brain which go on in the back stage behind our conscious mind in the similar manner as they do in conscious state. Only these activities are not focused into consciousness. The functions of it continue even during sleep and sometimes they are projected into our consciousness through dreams in sleep [Das, 2016].

What is dream? First of all, we will define what is sleep. Sleep is a state of the mind where activities of the perceptual quarters are absent. Only subconscious activities of the houses of the mind (memory, intelligence, emotions, and physical activities) remain active in sleep. When some of these subconscious activities come into consciousness by the same process as we get feelings from these houses in conscious state, we see dreams. The difference between conscious state and dream state is that - in conscious state, feelings from perceptual quarters are present at different consciousness levels; but in dream state, feelings from perceptual quarters are almost absent. Whatever we see in dreams that does not come from direct visual perception, but that comes from imaginary recapitulation from memory, so it is not as vivid as in reality. It is similar to the situation when we reminisce or recapitulate from memory in our conscious state.

Interpretation of a dream is difficult, as the dreams are not like something that subconscious sends in our conscious awareness in an organized way, as in intuition (a sudden, quick subconscious activities of our house of intelligence), or sudden retrieval of a memory (a subconscious retrieval action of the house of memory). But whatever we see in our dreams, they are the product of our subconscious' activities, that means the subconscious was working on them. But the projection of the product fails to represent it in an organized manner, for that, the dreams may not follow any logical form or proper time sequence - like surrealistic paintings. As we will discuss later, subconscious activities are guided by the emotional drives. For that, the subconscious projects into dream consciousness particularly those things which are associated with great emotional pressures. As per many literatures and also personal experience, being naked in public or being chased is very common in dreams. It may seem awkward, but the answer could be that if we think consciously of being naked in public, it will certainly evoke a great emotional embarrassment. So, this incidence is associated with great emotional pressure. Therefore, our subconscious surfaces the fact that is associated with strong emotional pressure just to release or express out its emotions. Have you ever experienced when you had been very hungry but had slept and you saw dreams about food?

Compared to our conscious activities of the mind, our subconscious can be much quicker and faster, as our subconscious' activities do not have the need to inform serially our conscious self. For that reason, we sometimes designate the term 'the sixth sense of us' informally to our 
subconscious, particularly in cases where we receive its alarming projection into our cognizance through its rapid undercurrent activities. Faster subconscious information processing has been recorded in different studies [Lewicki et al., 1992].

Our subconscious can act on involving wide area of knowledge basing on permutations and combinations of bits of knowledge including emotional memories that we gathered already in a more rapid and integrated way, the way which our conscious mind sometimes finds difficult to follow, though logical co-relation is also there and mechanisms of actions are the same. That is the reason, why we remember many insignificant facts that we do not want to; or we recall repeatedly many unpleasant emotional experiences against our will despite our strong resistance; or we sometimes do not feel to like some person or some place though we cannot explain why. But of course, we cannot affirm if these insignificant facts are really insignificant, or recalled emotional experiences are not those which have not to be urgently neutralized, or there is no logic behind our not liking something. As in many a case, subconscious eventually comes to have proved itself to be utter true. But yes, logic is of course there, as the processes of subconscious follow the same mechanisms as those of the conscious mind; but they could be much quicker and finer, and possibly more intricate than that our conscious mind can follow through its knowledge-searching. Subconscious can also avail comparatively weaker memories that are consciously irretrievable. So, more often than less, our subconscious finally concludes itself to be more reliable than our conscious mind. For that, we very often may be believed that 'our subconscious is wiser than our conscious mind'. In a considerable number of cases probably the answer is 'yes'. But yet, this is not always altogether true. A properly knowledgeable mind can explain subconscious' activities also. And there are scores when our subconscious may be falsified, and can mislead us; that what happens in obsession and seduction. For that, it is better for us to know about different quarters of our mysterious mind and the true views within the insides of them. Knowledge makes us wiser, that is necessary for the most intelligent person also.

Our subconscious' activities are run on their own by our emotional pressures, not having the necessity of volitional command or whip of our conscious mind. But their activities can be initiated by our conscious demand also, as is in the case of procedural memory which has been described later in this article.

\section{The Unconscious Mind}

Brain's unconscious activities are those which are not regulated by our conscious and subconscious drives - like regulation of the heart beats, regulation of the visceral functions, body temperature regulation, cerebellar maintenance of tone, posture and coordinated muscular activities, and so others. In majority, these are mediated through the autonomic nervous system, the higher center of which is located in hypothalamus of the brain. But any activity of any of the houses, either conscious or subconscious, may have influence on these parts of the brain; like emotion 'fear' produces dilatation of pupil and increased sweating, rigorous muscular activities increase heart rate and respiratory rate, and so many. The unconscious activities of 
brain can also be projected into conscious awareness, but not in a direct pathway. This could be mediated through indirect sensory pathway; like palpitation, visceral pain, urges for defecation and micturition, etc.

Reflex conditioned reactions have a major subconscious component. In some cases, it may have all three components of mind. In Pavlov's experiment with dog, the dog salivated at the sounds of bell when the sound of bell was conditioned with the sight of food. Here all the three components of mind are present in the process. Listening to the sounds of bell is a conscious activity of mind (input and information processing in house of memory), recalling or retrieval of another associated memory that 'this cue usually presents food thereafter' is a subconscious activity of mind because the organism did not consciously try to retrieve that memory. The effect of 'the memory of food' on hypothalamic autonomic neural center that controls salivary secretion, to increase the secretion of saliva is an unconscious component of mind. The difference between 'subconscious' and 'unconscious' is that we can do the subconscious activities consciously also. Like, when one driving a car, he can do it both consciously and subconsciously. But we cannot do our unconscious activities of mind on our own conscious or subconscious will. We cannot increase or decrease salivary secretion directly without any stimulus by our own will, either conscious or subconscious. We cannot make our heartbeat faster. But we can do those through indirect manners. Like, running a while or experiencing an emotion (e.g., watching a horror movie) will increase the heart rate. Thinking of food or experiencing 'hunger' emotion will increase the secretion of saliva (Fig.2).

In this article, I should keep away from 'cognitive unconscious' which means the unconscious machineries that make our perceptions and other actions of houses functional - like, how we process the visual images, or underlying mechanisms of retrieval of memory. That is beyond the objective of this treatise. Again, the concept of cognitive unconscious embraces a wide boundary taking materials from different arenas; some molecular mechanisms, some subconscious activities, some activities guided by hereditarily possessed memories (discussed later). 


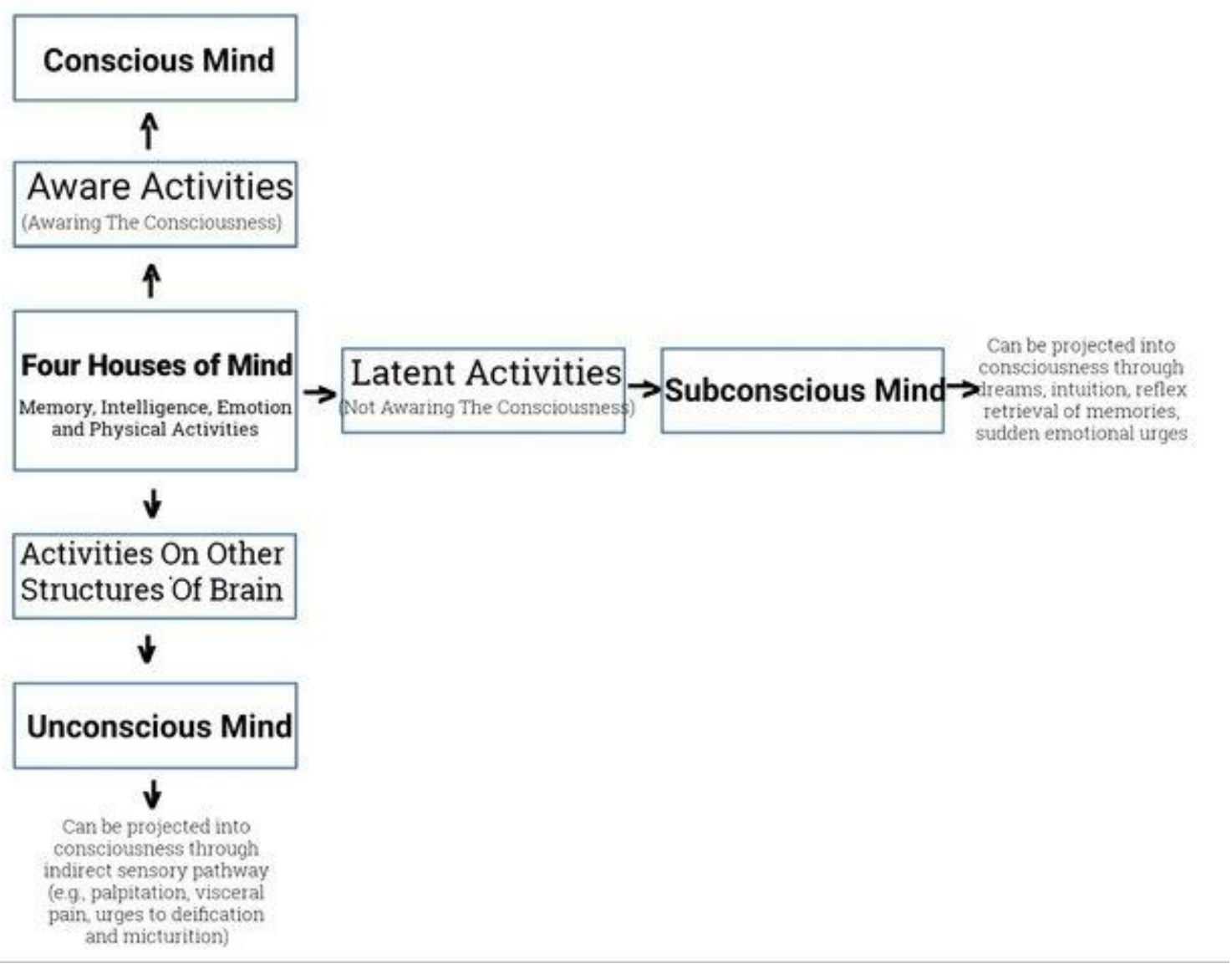

Fig. 2: Schematic Diagram of Mind [Adapted from Das, 2016]

\section{Why some activities of brain are conscious and some subconscious?}

All the activities of different houses of our mind do not come into our consciousness at the same time though they are there in subconscious mind. For example, when we read a novel, we look at the words that means our visual cortex is engaged in information processing; we interpret the language and grammar that means our frontal lobe is engaged in intellectual works; but their activities are all hidden. Consciously, we only imagine the events that has been described in that novel. But we can give attention to those activities also. It is like different tabs running different programs on a computer, but only one tab is exposed on the screen that we can watch and manipulate, others are being automatically run through some guides in the background. What are the mechanisms by which the activities of certain part of the brain come to our consciousness keeping the rest of the activities of the brain under the veil in subconscious mind? There are two possibilities. 
(A) One possibility is, through some unknown mechanisms, activities of some parts of the brain become conscious, but there are no common consciousness structure(s). A popular theory that has tried to explain this is 'global workspace theory' [Baars, 1988]. This theory suggests that when the activities of different parts of the brain become integrated through workspace neurons, then they project that into our consciousness. But there are serious questions about it. Many of our subconscious activities are highly integrated. Procedural activities or automatism which are subconsciously run are highly coordinated involving the activities of different parts of brain. But they do not come to our consciousness. Global work space theory does not clearly clarify how some organized functions of brain come to be conscious, that means it does not explain the very nature of consciousness or so called 'the hard problem of consciousness'. Global work space theory also does not posit the role of any specific organ for instigation and generation of contents of consciousness. According to GWT, contents compete to come into workspace or spotlight of theater, but the theory does not elucidate what precisely guides this competition.

Another theory in this category, forwarded by philosopher Daniel Dennett, is 'multiple drafts theory' [Dennett, 1991]. In this theory, Dennett postulated that there are parallel processings of interpretations and elaborations of sensory inputs at various places in brain at various stages of editing. Some of the contents in these drafts make contributions to consciousness, some others not. But there is no one place in the brain through which they have to pass to reach consciousness. But Dennett's theory is just a superficial narration and does not deal with the core mystery of consciousness. There is no doubt that there are multiple drafts or parallel processings in the brain. But how are they guided? If they are probed - which structure in brain do the job of probing? And why it probes selectively some and not others? Also, it does not disclose the mechanisms of probing. According to this theory, the subjective sequence of events is not the same as the objective sequence. To support his theory, he put forward Kolers' experiment of color phi phenomenon.

When two different colored circles, say red and green, were lit for $150 \mathrm{msec}$, one after another at an interval of $50 \mathrm{msec}$, the first circle seemed to move from its place to the second one's place as that happens in movies. But what happened to its color? The experiment showed the first circle appeared to change its color to the color of the second one at the middle of its illusory path.

The question is how we can see it to change the color before we see the second circle? Multiple drafts theory explains, as already said, consciousness does not experience on the same timeline as the things happen. But is it so?

The answer is different. Mind does not see always what eyes see. What we see partly depends on what we want to see, or what we anticipate to see. Actually, we do not see the color change, we only conceive it. Before seeing an object, the mind covers eyes' vision of it with its imagination that comes from or is built upon our pre-embedded associated memories [Das, 2018a]. What happens in this case has been explained in the following diagram (Fig.3). 


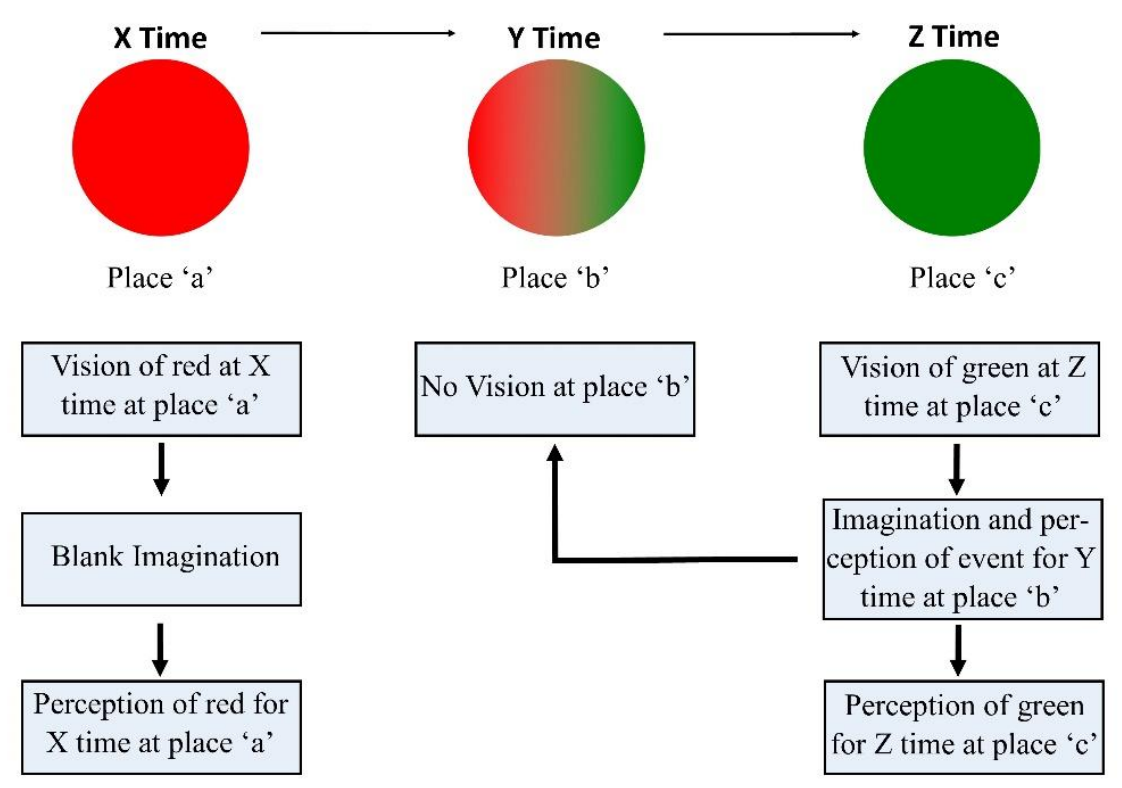

Fig. 3: Explanation of color phi phenomenon

Now, why mind imagines at $\mathrm{Z}$ time? Because we are accustomed to see motion of objects even if they may change a bit in shapes or colors - like objects moving from shadow to light with changed color, or moving objects changing shapes viewed from different angles or distances. And they are all depended on associative strengths of pre-embedded associated memories (for details see article Das, 2018a). Here guided by the previous cue, the mind perceives motions with color change without breaking the congruity of the event as it happens when we watch movies.

(B) The second possibility is there could be a central structure or group of structures in the brain through which some activities of parts of the brain come into consciousness where other activities do not. This general structure could be thalamus, basal ganglia, or upper brainstem, because damage to these structures is mostly associated with loss of consciousness in case of traumatic brain injuries and cerebrovascular strokes (either infarction or hemorrhage). In my medical experience, I have seen, in case of cerebrovascular strokes (either infarction or hemorrhage) involving wide area of cerebral cortical region, the patients have retained consciousness though in an altered or confusional state. But intracerebral hemorrhage in capsular region pressing thalamus and basal ganglia have sent the patients to vegetative state. In figure 4, there are two images of CT scan of two patients. The first patient had prosthetic mitral valve and was on oral anticoagulants. She had a large intraparenchymal hemorrhage in left fronto-parietal region with perilesional oedema. Posterior fossa structures - brain stem, cerebellum - were normal. The patient was admitted with headache and confusion and she never lost consciousness. After 2 days, when she was stable, I checked her consciousness 
thoroughly. She was well verbally communicative but a little confused and her GCS (Glasgow Coma Scale) was $\mathrm{E}_{4} \mathrm{M}_{6} \mathrm{~V}_{4}$. She could speak her name and other personal information, could count fingers, and obey verbal commands. But she lacked in some judgmental thinking, because when I first showed her four fingers and asked the number, she answered within seconds correctly (probably from memory retrieval), but when I took one finger off and asked again, she got confused and took long time before she finally answered with a smile of embarrassment for her inability. The given CT scan was done on repeat after 5 days of incidence. The second patient was admitted with acute infract in left parieto-occipital region and encephalomalacic changes in right gangliocapsular region, but the patient was conscious and her GCS was $\mathrm{E}_{4} \mathrm{M}_{6} \mathrm{~V}_{4}$. Though she was also in a confusional state, she could speak her name and was verbally communicative. The given CT scan was done at the time of admission. Most of the neuroimaging and other researches are in favor of the fact that thalamus, basal ganglia, and basal forebrain are the seat of consciousness [Fiset et al., 1999; Lull et al., 2010; Xie et al., 2011; Langsjo et al., 2012; Lutkenhoff, 2015; Weng et al., 2017, Zheng et al., 2021]. And the connections between thalamus, cerebral cortex, and limbic system maintain the integrity of the consciousness. Karen Ann Quinlan went to vegetative state after a cardiopulmonary arrest and died after 10 years while throughout this time she never regained consciousness. Her post-mortem analysis of brain showed disproportionately severe and bilateral damage in the thalamus as compared with the damage in the cerebral cortex [Kinney et al., 1994].

Now, if thalamus is the central seat of consciousness, our consciousness is also unified through intrathalamic connections as thalami are paired structures. Studies have shown that loss of consciousness is more severe in case of bilateral damage of thalamus than unilateral damage of thalamus [Moe et al., 2018].

Reticular activating system (RAS) is responsible for level of arousal, and maintains sleep-wake cycle. But sleep is not equivalent of unconsciousness. Though, some researches have found involvement of RAS in loss of consciousness [Yeo et al., 2013], RAS is not the seat of consciousness, because loss of consciousness can occur even without involvement of it. Quinlan had intact arousal in spite of extensive bilateral damage in the thalami because of relative sparing of extra-thalamic ascending reticular activating system [Kinney et al., 1994]. 

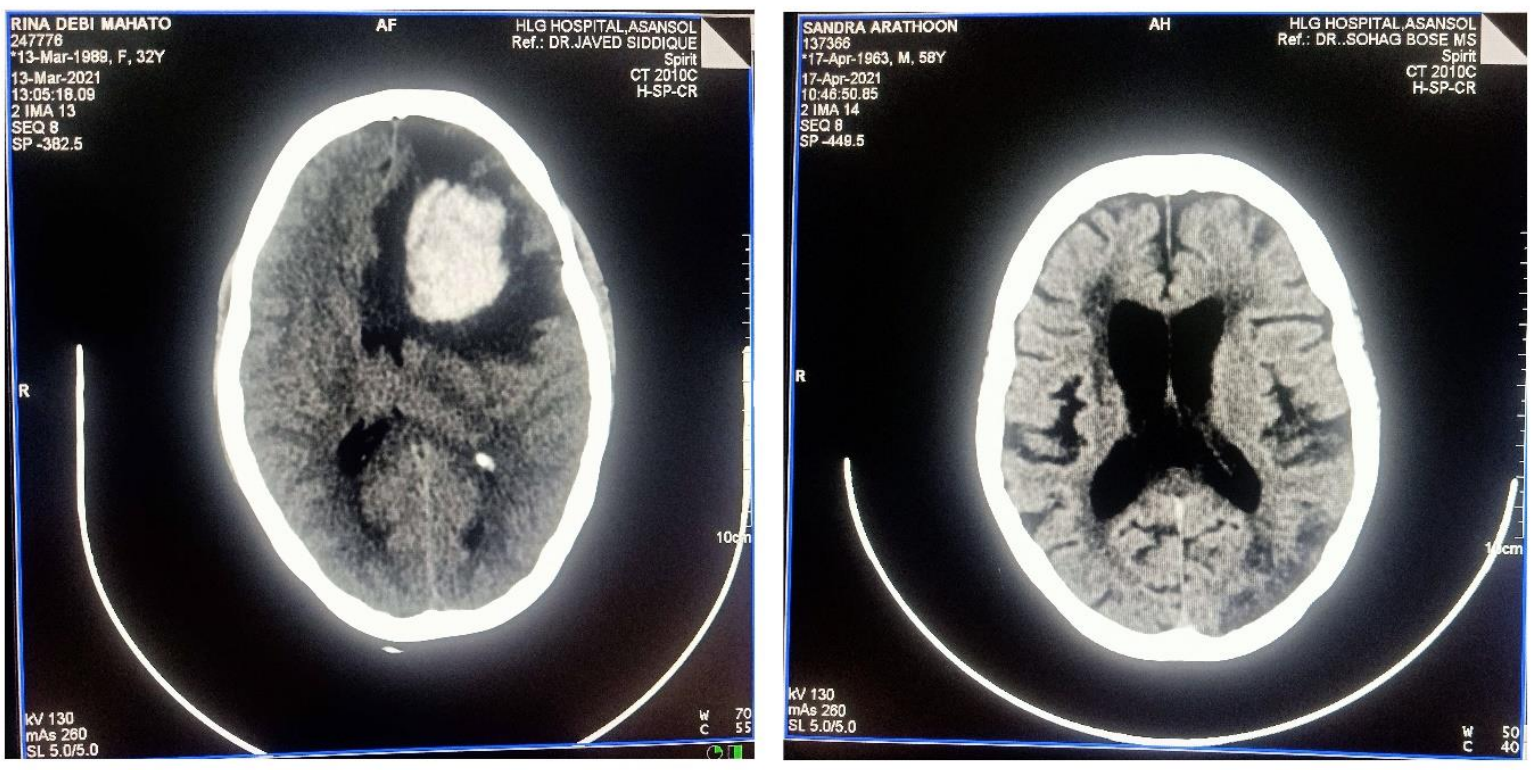

Fig. 4: CT scans of patients with (1) intraparenchymal hemorrhage in left fronto-parietal region, and (2) acute infract in left parieto-occipital region.

So, even though the parallel progress of several works - intellectual, emotional, perceptual, and motor activities can stream in our brain at the same time, only selective of them comes into our consciousness through thalamo-cortical network. Thalamus is also responsible for attention, though attention and consciousness are closely similar. The drive for attention comes from concurrent potential environmental stimuli (stimuli that either have high-graded perceptual sensation, or stimuli that have major effects on emotions - practically these two are inter-related) and the emotional pressure from the limbic system. And then, they are adjusted by the intellectual works of frontal cortex. So, for integrity of consciousness, connections of thalamus with limbic system and frontal cortex (through anterior cingulate) are so much important. This is the reason why when certain portion of the cerebral cortex is damaged sparing thalamus and adjacent structures, some specific functions of cortex and associative memories are disturbed, and functions of some arena of consciousness is lost; but consciousness, as it is, remains alive, though with confusional integrity.

So, we can hypothetically postulate thalamus play the role of central processing unit. It works in several stages. At the first stage, it gets information from environment through sensory organs, and gets emotional drives from limbic system. Then it determines the position about the effects of environment on emotional drives. At the $2^{\text {nd }}$ stage, it employs house of intelligence (frontal cortex) for attentional activities and future actions in favor of emotional drives after considering environment. In the $3^{\text {rd }}$ stage, it brings necessary contents and activities into consciousness through attention, and engage other activities in automatism without attention. Thalamus does this by conferring special attributes (some electro-chemical changes in state of neurons) upon destined neurons of specific regions of the cortex through thalamo- 
cortical pathways (Fig.5). The basal ganglia play an important role in automatic functionality. The whole process is executed in a very short time, even within fraction of seconds, while rendering intermediate processings beyond attention subconscious. For that, while we pay special attention to any object in our visual field, we cannot often follow why it is so special, being ignorant of the underlying processings as described.

Split-brain experiments pioneered by Nobel laureate Roger Sperry, show our two hemispheres act independently, like motor activities of left-sided limbs are controlled by right hemisphere, and vice versa; visual information processing of the right-sided visual field done by the left visual cortex and vice versa [Gazzaniga, 2005]. But even though perception is divided in splitbrain patients, their consciousness remains undivided [Pinto et al., 2017]. This emphasizes that seat of consciousness does not locate in cerebral cortex, but it resides in much deeper structures below the level of corpus callosum.

Unilateral neglect is seen in patients with considerable damage of one-sided cerebral cortex. Here though consciousness remains functional, due to loss or damage of one-sided cortex, it's functional perimetry becomes constricted. As perceptual sensory nerve fibers decussate before reaching thalamus, this constriction of attentional world occurs in contralateral side of the damage. Though some studies indicate unilateral neglect can occur also in thalamic strokes without any cortical involvement, [Karussis et al., 2000; Renzi et al., 1989], findings in most of the researches do not support this [Bartolomeo et al., 1998; Leibovitch et al., 1998; Behrmann et al., 2003; Hillis et al., 2005; Buxbaum, 2006 - review; List et al., 2007; Verdon et al., 2010]. Whatever it is, the thalamo-cortical network of one-sided cerebral cortex is disrupted in different degrees in patients with unilateral neglect. This unilateral neglect also involves imaginary thinking. Bisiach and Luzzatti took patients with damages in right-sided cerebral cortex and showing left-sided neglect. Then they asked them to think of the famous Cathedral Square of Milan when they entered it from one side. They described all the things on their right side and ignored things on left side. But when they were asked to imagine to enter it from the opposite side, they described again all the things on there right side that were ignored before [Bisiach \& Luzzatti, 1978; Blackmore \& Troscianko, 2018]. Here all the memories have been shared and stored through corpus callosum in both hemispheres. But perimetry of consciousness of visual field has been constricted. When right-sided thalamus probes rightsided cortex for imagining left-sided visual field, it fails in its job.

Then again comes the question - 'Is this consciousness-structure of brain passive or active?'. If it is passive, then there is no control of us on that which activity of mind will come into our consciousness. But that is not so. So, we have to presume this consciousness-structure is active. This activity of consciousness structure is guided by environmental stimuli through sensory perceptions, emotional pressures from limbic system, and intellectual workings and adjustment from frontal cortex. Both our conscious and subconscious are guided by the emotional drives that is called primary drive (Fig. 8). Particularly, those environmental stimuli act on consciousness those have impact on emotions, and subsequent intellectual proceedings eventually culminate in our conscious will. That is why I wrote in abstract why reading a telephone directory from cover to cover just for the sake of reading is so difficult. Because 
there is no primary drive. In case of subconscious activity, previous input of environmental memory works instead of concurrent environment. Previous input of environmental memory guides our conscious activity also. Now, whenever there develops a conscious or subconscious wish, it orders our parts of brain to work accordingly. For example, to try to solve something, this wish (conscious or subconscious) orders the house of intelligence ${ }^{3}$ or frontal cortex; to try to express emotion, this would order the house of emotion or limbic system; to try to do some motor activities, it would order the house of PA or premotor/motor cortex. Now these activities may remain subconscious or may enter into consciousness, both by this common consciousness structure (Fig.5).

A recent study showed dysfunction of anterior insular cortex rather than thalamo-cortical pathway in graded propofol induced anesthesia, predicting the role of AIC (not thalamus) as the gateway of conscious access [Huang et al., 2021]. Further studies are needed to conclude about that. Moreover, gate(s) not only just makes selective sensory perceptions conscious, but also renders selective brain activities (intellectual, emotional, and motor) conscious or subconscious. The question is - "are they controlled by the same structure or by different structures? Whatever it is, the diagram in the figure 16 has taken thalamus as the central processing unit for consciousness for both the processes.

\footnotetext{
${ }^{3}$ \# Intelligence is serialization of received or stored information in such a sequence that would produce a specific outcome towards a target [Das, 2016].
} 


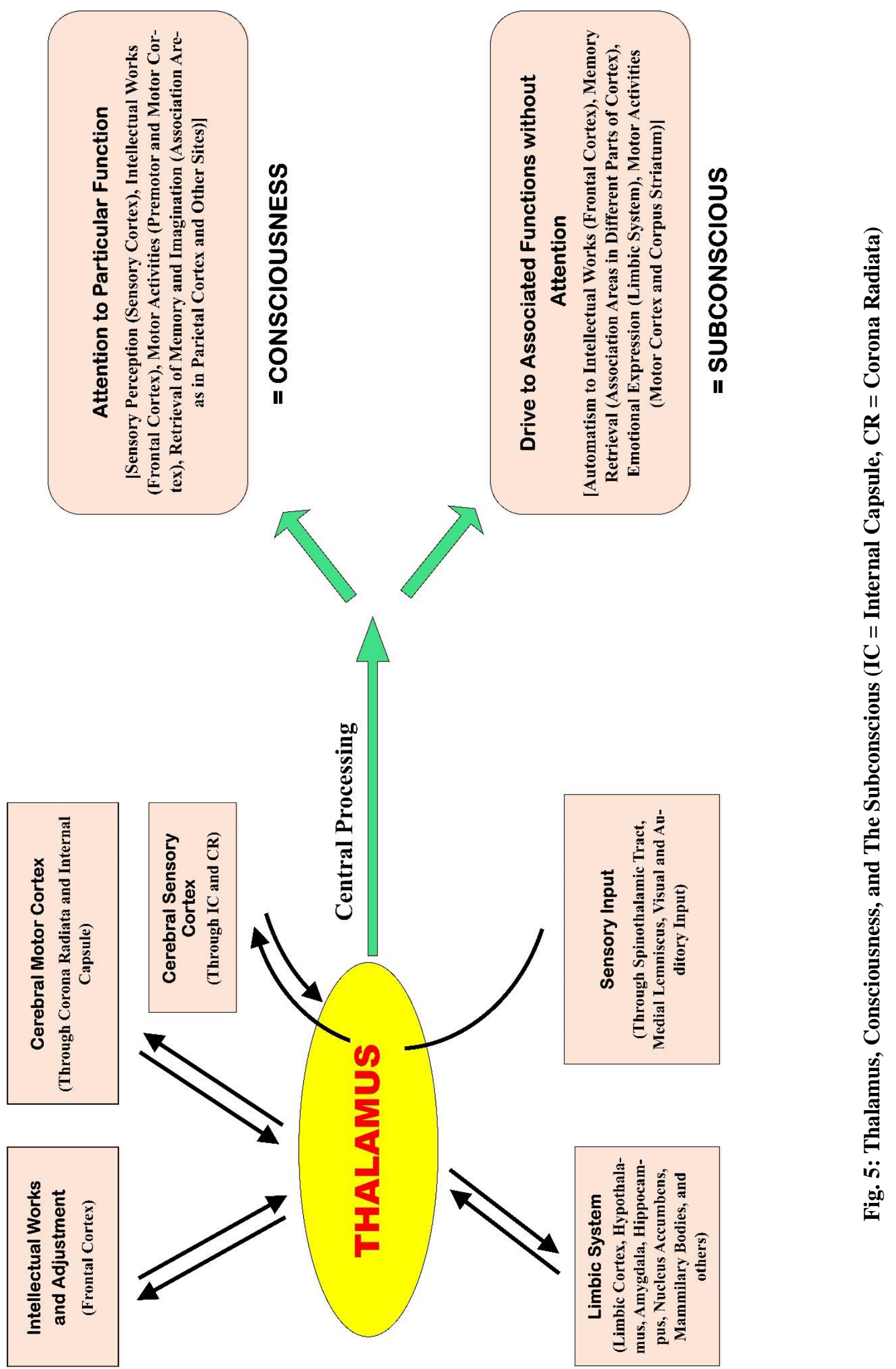


However, with further more researches, we may be able to locate the actual sites of consciousness, but how these specific sites or structures bring certain functions of brain into our consciousness is far more beyond our understanding. If we think of our experienced inner mind, our philosophical thinking, our ideas, our efforts to solve problems, consciousness builds a great inexplicable mystery to us. How simple neural mechanisms can create this wonderful experience of inner self - is called 'the hard problem of consciousness' as David Chalmers stated [Chalmers, 1996]. As Chalmers said, most of the literatures either ignore this entirely or put it off aside for future days. Even sometimes it may be declared answered. But we need to go a long way for complete explanation of that. However, Chalmers disagreed with the reductionistic property of consciousness. According to him, consciousness cannot be explained by the mere physical laws of the universe. But we do not disagree.

That day, I suddenly noticed a patient unconscious in the critical care unit, and not responding to verbal stimuli and also well with painful stimuli. But her vitals (pulse, $\mathrm{BP}$, etc.) and $\mathrm{SpO}_{2}$ (oxygen saturation in blood) are all within normal range. I remembered the night before I gave her excess injection Lasix to combat with her left ventricular failure. So, there must be hyponatremia. I checked her sodium level in blood. It was $113 \mathrm{mEq} / \mathrm{L}$. I started to infuse 3\% $\mathrm{NaCl}$ slowly to her. She gradually came to the stage 2 level of verbal response of GCS scale making incomprehensible verbal sounds, then stage 3 level - that is she started irrelevant talking without any coherence. Then she came to the stage 4 level - that is confused stage with some disorientation (questioning 'where am I?', 'how did I come here?', 'What time is now?', etc.). Finally, she became fully conscious and oriented with time, place, persons. If a little sodium can do this marvelous thing, how can I deny consciousness is not dependent on the physical properties of this universe?

Consciousness does not escape physical laws of our universe. Instead, it is a marvelous (? or accidental) development out of the cosmos of matter, energy, space, and time maintaining every physio-chemical law within the boundary of our universe.

Here in the following section, we should not say dare, but humbly think of a possibility to explain the hard problem of consciousness.

\section{Hard Problem of the Consciousness}

If we think of our experienced inner self with its intellectual works, ideas, feelings as a whole, it creates a great puzzle to us to explain its mechanisms. But if we carefully introspect, we will see consciousness is composed of a number of parallel series of feelings. These series of feelings could be perceptual (visual, auditory, etc.), emotional, recapitulation from memory, intellectual and physical (Fig. 6(b)). At any moment, the consciousness constitutes one or more number serial feelings from different quarters. We, at a time, can feel two serial feelings from two different quarters - as we see, we also hear. But at a time, we cannot feel two series of feelings from the same quarter - like at a time, we cannot watch two entirely different events consciously. We have to rapidly switch over on them. We cannot experience two emotions at 
a time - like anger and love. We have to quickly switch over on them. Similarly, we cannot calculate two bills simultaneously at the same time (intellectual feelings). But we can calculate a bill while listening to a music. We can feel 'fear' in mind and do mathematics simultaneously before examination. These feelings are similar to the bit of feeling that was first felt by a primitive organism as a sense of pain that directed the organism's movement away from a noxious stimulus. That first felt bit of pain by a primitive organism through some machinery equivalent to today's developed nervous system signalized the birth of 'consciousness'. More the animals evolved, had the feelings been diversified in their sensations differing in their anatomical, physiological, and biochemical properties. In man, these feelings have been diversified into wide varieties of sensations different in their qualia - coming from direct senses, memory retrieval, emotional impulses, and intellectual processes. These feelings are generated by certain electro-chemical alterations of states of specified neurons. These bits of feelings can be stored as memories for a time span by an alternate mechanism in specified neurons and can be retrieved or relayed to other specified neurons. Memory retrieval is recollection of these information from the stores that may or may not come to feelings depending on conscious or subconscious activity. When we think of the letter 'A', we think it by the stored visual or auditory impression of it. So are for words and sentences. Intelligence is serialization of the memories of these bits of feelings in such a sequence that would produce a desired outcome (which is fostered by different emotional drives). For example, when I am hungry, I get a feeling of 'hunger' which is perception as well as emotion ('hunger', 'thirst', 'sex', and 'love' have both emotional and perceptional features; Das, 2016, 2018). Next this bit of feeling invokes the bit of feeling of visual memory of desired food. Subsequently, that bit of feeling educes the bit of feeling of visual memory of where the food is kept. The first bit of feeling is an emotional drive, the second two are visual perceptual feelings (retrieved from memory) serialized by house of intelligence (frontal cortex) through cortico-cortical interneuron connectivities. These inter-neuron connectivities are selectively more strengthened through repeated use in specific ways, making our thinking more fluent. Learning of language with its rules has made the process of memory retrieval and intellectualization more sophisticated. These bits of feelings are engendered by the altered electro-chemical state of the related cortical neurons, and as already stated this altered state is endowed by the selective drives coming from the thalamic neurons which in turn is regulated by emotional drives coming from limbic system.

Whenever there are deficiencies or ambiguities or small time-gaps in case of any perceptions, recapitulated memories from stores of houses fill up the gap depending upon the strength of associated memories as well as the corresponding emotional state of the mind (for details about perception and illusory coefficient $\gamma$ of any perception, see Das, 2018).

Level of consciousness for each of these series of feelings do not always remain at the same level at a time. When you are solving a mathematical problem, your intellectual feeling's consciousness level keeps at the highest, but visual and auditory perceptual feelings' consciousness level remains low. But when you are watching a movie, the reverse thing happens. We experience our parallel conscious feelings with different intensities. It is not the 
question of arousal. Even in fully conscious state, we do not experience each of our parallel feelings with the same intensity. Let us explain it with further examples. Suppose, you are driving a car, but your mind is engrossed in some deep thought. Now your visual feelings of watching roads, traffic lights, etc. are not as vivid as when you watch a movie. Your auditory feelings are there, but those are not as vibrant as when you listen to a music. Same is true for other parallel feelings. What is the most intense in your mind is your intellectual feelings of what you are deeply thinking of. You cannot say other feelings are totally unconscious or subconscious. We can say them semiconscious. Again, when you are reading a book, you imagine the content of the book consciously, the visual perception of the words of the book is minimally conscious, and interpretation of language and grammar is subconscious. However, subconscious activities leave an impression upon the mind. That is the difference between sleep and anesthesia. After a good sleep, you feel you have slept. Because there were subconscious activities during sleep. But after recovering from anesthesia, you cannot feel what happened in between the times, because there were no subconscious activities.

Again, each of these serial feelings has refractory periods. That means to get vision of two subsequent things we need one-tenth of a second in between. Practically, each series of feelings is composed of fractionated bits of feelings, but we do not experience them as fractionated bits, instead we experience them as a continuous one. The reason may be the change in the electrochemical state of neurons that brings about conscious feeling, lingers for some time, so that the feeling can be merged with the subsequent feeling brought about by the change in electrochemical state of same or other neurons by the upcoming events. When we recapitulate from memory, we actually recapitulate stored past experience of feelings of different quarters, e.g., perceptual, emotional, intellectual, physical. Another change in electro-chemical state of neurons stores these memories of these feelings, and that in need, can evoke the change in electro-chemical state of destined neurons through intermediate neurons to produce same kind of conscious feelings. These recapitulated feelings are weaker or less vivid than that experienced in reality. Difference with emotional feelings from that of perceptual and other feelings is that emotional feelings have been associated with motivation as described in emotion model [Das, 2016, 2017]. Perceptual feelings are informative and do not have attached strong motivation, yet we do not like excessive pressure, temperature, light, sounds, and try to avoid them. Here motivation is engendered by the fact that the altered electro-chemical state of the responsible emotion producing neurons is an unstable state, and this state has a propensity to change into another more stable state. In case of perceptual feeling, the altered electro-chemical state just dies out after a time span. Self-consciousness only emerges because that bit of feeling of 'hunger' by me can only be quenched if the food is taken through my mouth. All our emotional drives are driving us all throughout our lives for the maximum (? Or optimum) satisfaction of them but not for satisfying others' emotions; and thus create our selfidentity and our selfishness. Some may argue, but 'love', 'altruism', 'empathy' are also emotions, the benefits of which are directed to others. Purposes of every emotion have been described in details in my earlier literature. Our life can easily be compared with that sodium craving for water or moisture to get its stability through making a stable compound, but there 
is a leak. Think there is a cistern whose utmost desire is to be filled up with water at its brink. And it has engaged you to the task of fulfillment of its desire. But there is a leak at its bottom. So, you are laboriously trying to fulfill its desire to fill it up at the brink, but can never be satisfied that your work has been done even at the endpoint of your life, because the leak is always draining. Today you are hungry, and treated yourself with a grand feast, tomorrow you will again feel the pang of hunger. Once billionaire man is still searching for happiness, fulfillment. Schizophrenic patients suffering from emotional apathy cannot execute goaloriented thinking, they are automatically obedient to others' orders (automatic obedience), and show poor self-care and self-hygiene.

Now, it is comparatively easier to imagine the mechanisms of perceptual, emotional, physical, and recapitulated feelings, but it is a bit tough to imagine the feelings of our intellectual works. Man is in front of other animals, because it has more frontal lobe in brain than others. Our intellectual works clearly differentiate us from all other animals. But first of all, we should define what intellect is. Intelligence is serialization of received or stored information in such a sequence that would produce a specific outcome towards a target [Das, 2016]. This is a marvelous work from our house of intelligence - associating and serializing of bits of feelings from same or different quarters in a particular sequence to give direction to the desired bit of feeling. And as we repeatedly reiterated, this work as all others of our different houses is spurred by the emotional primary drives (fig. 8). That is why we said in abstract reading a telephone directory from cover to cover is so difficult for us, because there is no primary drive behind it. Those who do mechanical jobs at workplaces, they know they would get a fat salary at the end of the month, by which they can serve their emotions. These emotional primary drives we can feel consciously, but even when we do not feel them consciously, they work subconsciously.

Let us elaborate the process of intellectualization a little further. Primitive man experienced that when two stones are frictioned with each other, they give sparks of light and fire. They also experienced that in dry grassy land sometimes from these sparks of fire (which were produced by the friction of the dry plants), fire was caught to the dry plants. And they also experienced when animals were partially burnt in this fire, their flesh tasted good. Here, the first one is recapitulated feelings from physical and visual memories. The subsequent feelings are recapitulated feelings from visual memory. Then the last one is recapitulated gustatory feeling. The desired feeling is gustatory feeling. So, the primitive brain of the man sequenced these three events in following way - If they could rub two stones before dry leaves and plants, the sparks of fire produced by the friction of stones would catch fire to the woods; then if they put the flesh of the dead animals in that fire so that those got partially burnt or roasted, they would ultimately get more tasteful food. So, they learned cooking. And all of this process of intellectualization are driven by our emotion 'hunger'.

Our house of intelligence, situated in the frontal lobe of brain, is always doing this thing taking information that we have gathered in the house of memory, then serializing them in a specific sequence, and finally producing the output, all according to the desire which is being determined by the house of emotion. We can call it as logical serialization of bits of 
information. But it actually is the most probabilistic serialization of bits of information. We know $1+1=2$, and we believed in it through numerous regular experiences in our life. But we cannot prove how one plus one is equal to two, and not otherwise. The proof actually depends on frequency of experiences or strength of associated memories. So, intelligence's logical serialization better should be called the most probabilistic serialization. We did not experience if we keep two apples one after another in a basket, they become three apples. As per Jean Paget's developmental studies with children, logical thinking develops between 7 to 11 years of age, when they have gone through some experiences in life. Artificial intelligence is created by human. They are not naturally developed. We impose upon them our self-experienced rules in the form of algorithms. But learning from experiences is also going to be an essential feature of future AI. However, for simplicity, we described intelligence as logical serialization of stored memories/information in this article.

This intellectual product or specifically serialized bits of feelings can also be stored as memories (intellectual memory) and can be used in future. When we do mathematics, we also apply previously learned serializations. And through communication, we can transfer this knowledge to the following generations also. A child of today learns a lot of knowledge and mathematics within 10-12 years of his age. Actually, he stores in his memory the already sequenced events done by our earlier men. In the example of 'learning of cooking', experiences and sequencing have not been accomplished in one generation. It took many generations for the primitive brain of the man to achieve experiences and sequence them to get to the ultimate learning of cooking. One intellectual experience which was stored as intellectual memory has been transferred to the next generation through different modes. Today, in this age of information, this transference is much easier.

Now it is interesting. If intelligence is serialization of bits of memories, we cannot think of anything where there are no experienced memories, i.e., there are no bits of information regarding that matter in our memory. That is true. Innovation in science and imagination in arts are similar. When we do artwork, we try to imagine something new which should be appreciated as a new and creative work. But in this regard, it must be known that we cannot imagine something that is totally unrelated with what we have experienced in our life. For instance, when someone is imaging an animal like Gryphon, he has the experience or knowledge of a lion and a bird. Chance discoveries or inventions occur in science. But there intellectual process is absent. Mind intellectualizes it with further investigations after it has been discovered. Leopold Infeld and Albert Einstein, in their book 'The Evolution of Physics', presented a beautiful introspection regarding why it is hard for us to imagine an extra dimension. When we watch a movie, we see the characters on the screen are moving, talking, playing, etc. If those characters were real on the screen and they existed in a world of their own, it would have been hard for them to imagine there exists another dimension of depth. We cannot think that that we have not experienced, though sometimes mathematical possibilities indicate the chance of existence of many things. What we cannot think, does not mean that they cannot exist. 
In case of perceptual feelings, if there are small gaps or any deficiencies, those deficiencies are covered up by the imagination neurons that through taking help of pre-established knowledge and experience, i.e., pre-embedded memories, fill up the gaps in the most probabilistic way.

Now, every series of these feelings are interconnected with inter-neurons making one's effect active on another. Visual perceptual feelings of food or sexual objects would evoke emotional feelings of 'hunger' and 'sex'. When one is engrossed in deep intellectual thoughts or reading an interesting book (imaginary recapitulation), his real visual feelings would be blurred, and imagination (a kind of recalling and intellectualization from past memories) would be activated to produce imaginary visual feelings from stored memories. Even our different perceptual feelings have effects upon one another. When we watch a movie, we feel that verbal sounds are coming from the mouth of the characters, not outside the screen.

Though the whole process is very intricate engaging specified activities of millions of neurons, yet it is not altogether unimaginable.

In a nutshell, emotional feelings are our goals, intellectual feelings are our means for optimum emotional gratification (optimum because sometimes delayed gratification is permitted by intelligence to get optimum or better result). And perceptual and memory feelings provide information for the best ways to achieve that gratification. So, the feelings would have effects on one another in the following way (Fig. 6(a)).

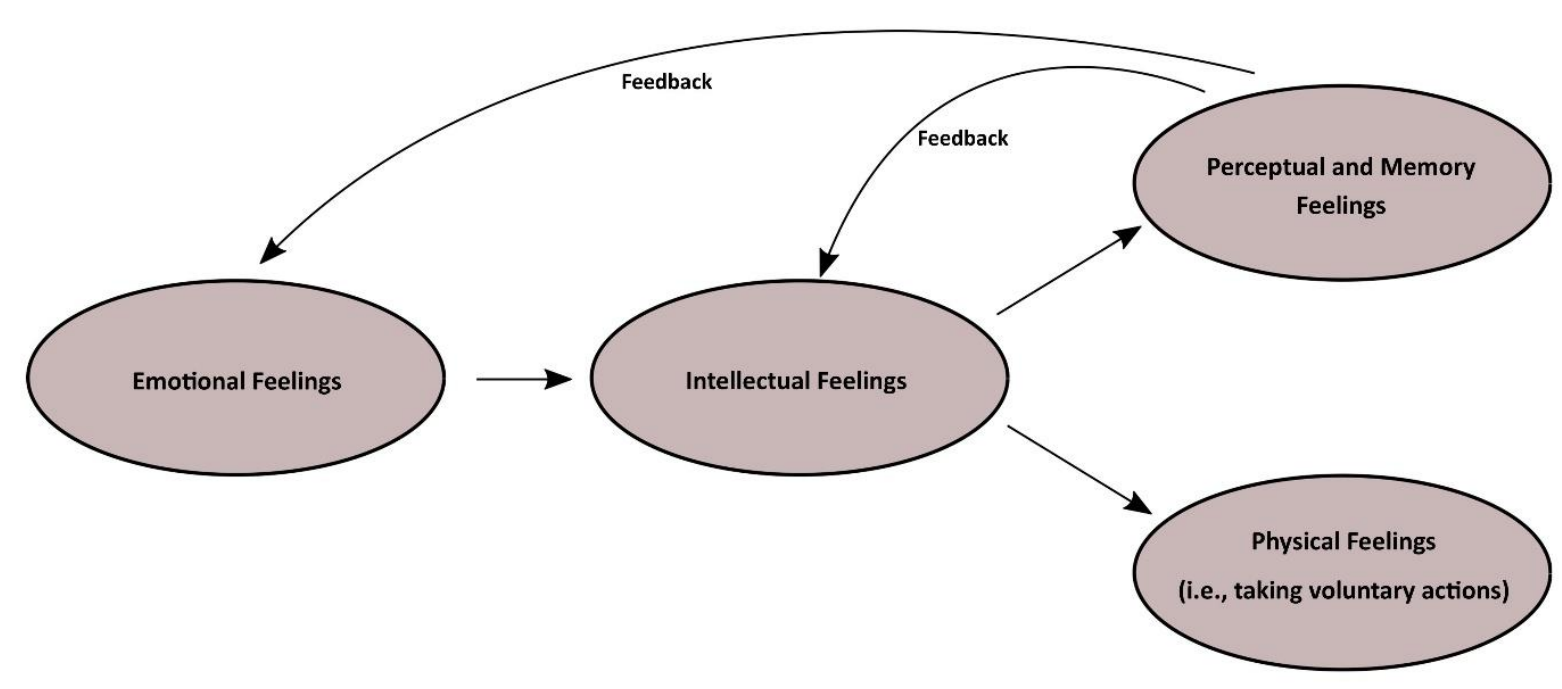

Fig. 6(a): The effects of conscious feelings upon one another. 


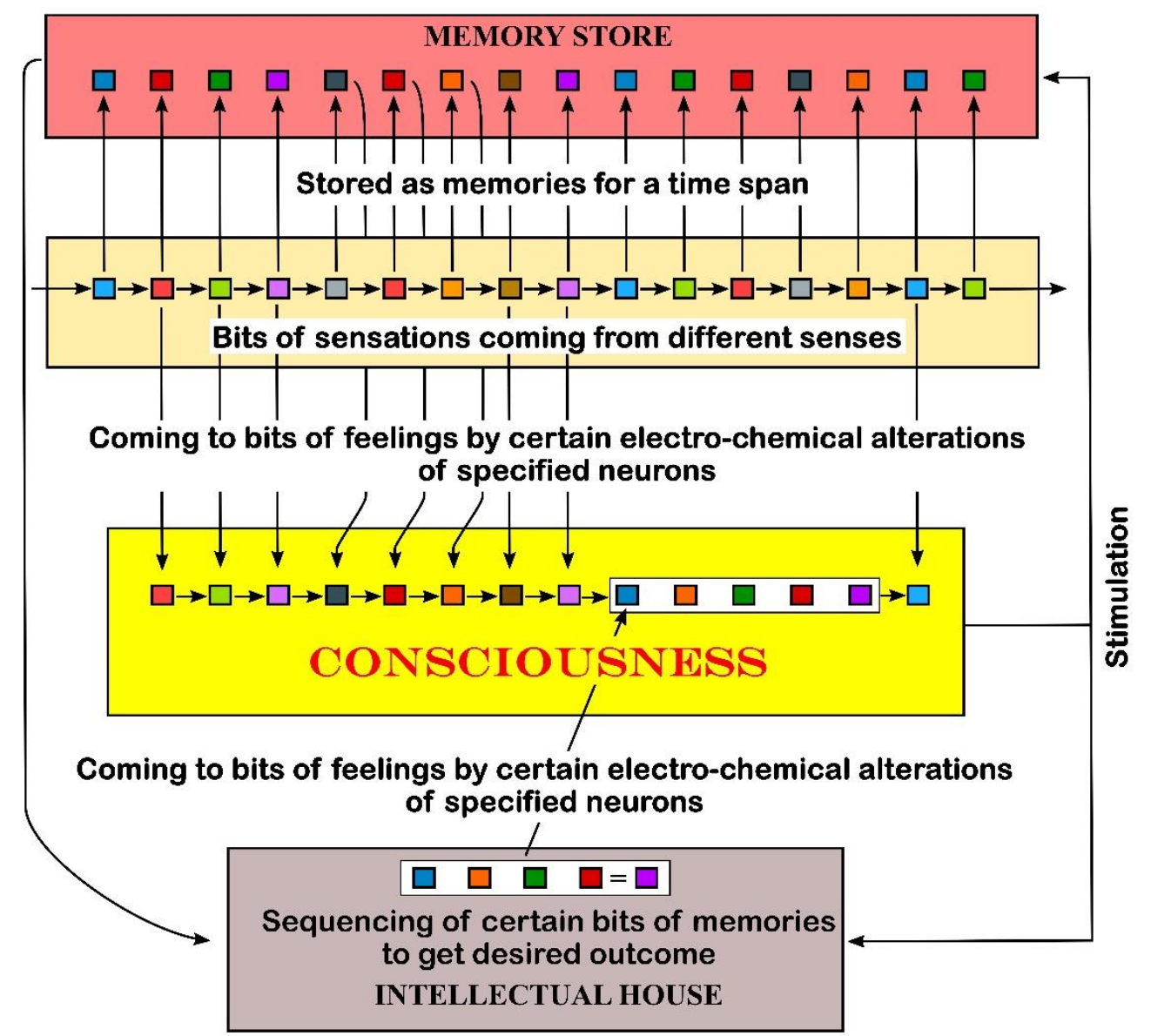

The process is executed under the influences of emotional drives from limbic system through thalamus

Fig. 6(b): Mechanisms of Action of Consciousness

(The diagram has described conscious experience of different feelings in one series. Consciousness is composed of a number of such parallel series of feelings.)

Here I must clarify another issue to make the whole picture complete. As already stated, our conscious activities can engage a single activity of a particular house or perceptual arena of our mind. All the parallel series of conscious feelings come from different quarters of the mind. But can subconscious include more than one activity of a particular house of the mind? Or can conscious and subconscious both engage two different activities of the same quarter of the mind at the same time? The answer is not. When you read a book or drive a car, you faintly consciously engage your visual perceptual processes for watching words and roads respectively. But at the same time, you cannot engage your visual perceptual process for watching a different visual imagery. You cannot watch a movie while driving a car or reading a book. But you can listen to a music while you drive a car or read a book, because auditory perception is not much needed in driving a car or reading a book. If serious need occurs, 
conscious or subconscious can quickly switch on through the effect of emotional impacts. Again, while listening to radio seriously, e.g., listening to radio news, you can experience a visual imagery. Like while you are travelling on a train, you can watch visual imagery through the window and at the same time, you can listen to radio news seriously. So, consciousness cannot engage more than one activity of our houses or perceptual quarters at the same time. Subconscious activities are devoid of perceptual works, but it can engage more than one activity of the houses at the same time. When you are watching a movie, your house of intelligence can try to solve some of your worries subconsciously. When you are reading a book, interpretation of language and grammar involve both houses of intelligence and memory. When you are driving a car, your house of physical activity performs memorized algorithmic muscular activities subconsciously.

During sleep, all the conscious activities of all the quarters of the mind remain shut off. So, sleep is the time for the maximum activities of subconscious. In conscious state, we are always get diverted by the environmental stimuli. Any buoyant family or friends gathering can obliviate your worries, and distract your conscious efforts for solving some of your worries, but they are run subconsciously. In sleep, they get the highest chance of their subconscious activities.

This is the reason why sleep is so essential for the higher evolved brain. Many may argue, but the real purpose of sleep is not taking some rest from the conscious world, but to give the optimum scope for the activities of the subconscious world. During sleep, emotional expressions occur, intellectual workings are done, potentiation of memories are accomplished according to the emotional needs. And all of subconscious activities are driven by the primary drives or emotional drives (Fig. 9). So, after a good sleep, you can feel refresh, new ideas come to mind because of intellectual work up. It is just like restarting a computer closing unwanted applications and refreshing everything ready to start.

If subconscious activities were not there, we would have been carried away by the environment, neglecting our own emotional drives and pressures. And that would not have counted good from the perspective of survival.

It is hard to perceive other's mind or other's consciousness. But we can predict it, because consciousness depends on not only perceptual feelings, but also appreciation of four major houses of mind.

(1) Emotions: We all humans do not possess all emotions everybody, and even if we possess them, we do not possess them in the same magnitude. Emotions give the background color of the consciousness. When we think about how deep is Mariana Trench, it is not just an inquiry about information. The passion of curiosity is working behind it. Without it, it would have been just a query among thousand others. Now, this emotion could be absent, or present in different magnitudes among different people. So is true for all other emotions. Depending on those, it would be ascertained how one's background feeling for consciousness is. 
(2) Intelligence: People with higher intelligence can correlate lots of information, and appreciate them with rationalization. And so, their thoughts, actions, and behaviors are also guided accordingly. People with lower intelligence, lacking in this appreciation, often guided by the instant emotions.

(3) Memory: People with higher MQ, can, at a time, recapitulate lots of associated information. It makes his consciousness more elaborated and fluent. It also helps his house of intelligence to work comprehensively.

(4) Physical Efficiency: The house of physical activity also renders some attribute upon consciousness. A well-built, highly physically efficient person would feel an energetic feeling. His consciousness would get some positive vibe from his physical efficiency.

Compared to humans, animals' IQ and MQ are low. So, their consciousness is restricted to mainly emotional urges, and subsequent behaviors and actions.

\section{Procedural Memory: A Good example of Conscious and Subconscious Activities at Different Levels.}

Usually memories, upon their mode of retrieval, has been classified into two groups.

(1) Declarative Memory - the memories which we recall consciously. It includes all conscious recollection of facts and events. (2) Procedural Memory - the memories whose retrieval occurs unconsciously, and which come effective without awareness of conscious mind; like riding a bicycle, playing a musical instrument etc.

But there is some misconception about procedural memories.

Procedural memories very often have been linked to those memories which have been learned or acquired through repetitive processes over time, or through different phases. But that is not true.

The true fact is -

(1) Procedural memory is recalled subconsciously. But we can recall it consciously also. While one is driving a car, he recalls how to drive a car subconsciously. But he can perform the task recalling it consciously also.

(2) Procedural memory does not mean learning only motor skills. When someone is reading a novel, he faintly sees the printed words. Here, his visual perceptual feelings are conscious, but at the minimum consciousness level. He pays no attention to the language and grammar if he is an expert in that language. Here, the comprehension of language and grammar is being accomplished automatically in his subconscious mind. Only, he, taking the help of his stored memories, imagines the content of the book, which keeps at the highest consciousness level for that time (Fig. 7). 
(3) The automatic performance of recalling of memories is not only applicable to the memories which has been consolidated by the repetitive processes, but automatic activation is also applicable to the memories which has been consolidated through emotional charges. As learning to drive a car may involve great emotion. It may not be a memory that has been consolidated through repetition. An enthusiastic student may learn it very quickly and then can perform the task automatically and subconsciously. Even one single event of learning, consolidated by great emotional charges, can make a process feasible for automatic performance. It all depends on the associative strength between stimulus units and target activities in the process. So, there may not be serial phases in associative learning to render a learned activity automatic.

(4) Besides recalling of memory, intellectual processes, emotional adjustments can also be performed automatically. In case of comprehension of language and grammar while reading a novel, there is automatic performance of 'house of intelligence' and 'house of memory'. In case of riding a bicycle, there is automatic performance of 'house of memory' and 'house of physical activity'.

(5) Automatism of motor activities involve corpus striatum (caudate nuclei and lentiform nuclei), because involvement of corpus striatum in pathogenic lesions tends to lead disappearance of associated movements, e.g., swinging of arms while walking [Koshi, 2018]. However, basal ganglia may play roles in automatism of other houses also [Packard, 2002; Lanciego, 2012].

So automatic recalling of memories, which according to the popular notion is known as procedural memory, is primarily the subconscious activities of any one or more of the houses of our brain initiated by our conscious demand, being effective in a practical way [Das, 2016]. Some associated functions may be at minimum consciousness level too. For example, while you are riding a bicycle with some deep thought, physical movements are subconscious, but visual imagery of the road may be at minimum consciousness level. 


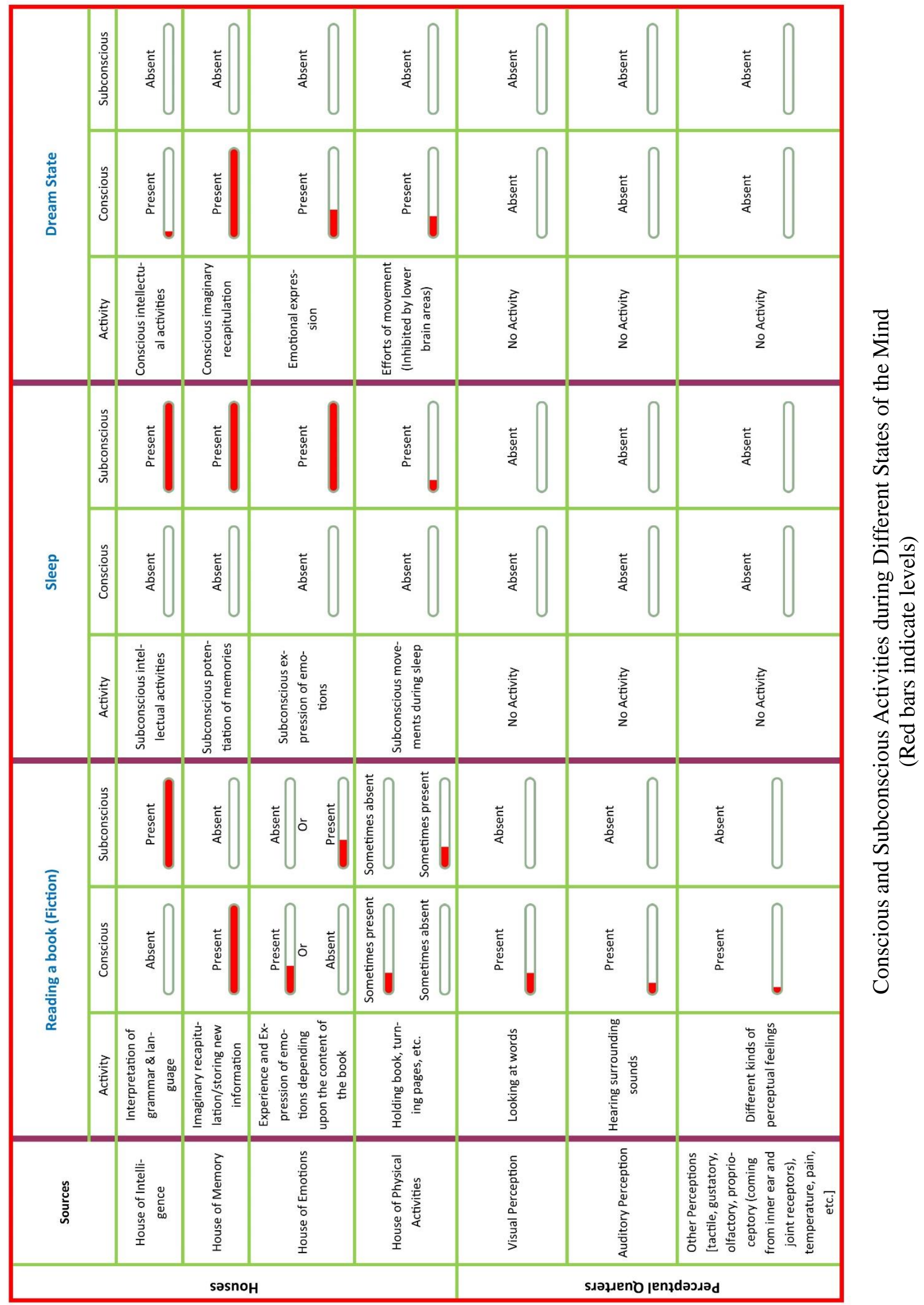


Whenever our conscious mind chooses to pursue a goal, it automatically involves our subconscious mind too. When one chooses to read a novel, he automatically involves his subconscious mind also to interpret the grammar and language (subconscious activities of 'house of memory' and 'house of intelligence'), when one chooses to drive a car, he automatically involves his subconscious mind also to regulate the motor activities (subconscious activities of 'house of memory' and 'house of physical activities').

But subconscious is always being auto-activated also. But for that, emotional pressure is essential (elaborated later). For example, someone is driving a car, his conscious desire has put subconscious to take the necessary actions. Now, if suddenly a car from sideways comes in front of it, he will startle in fear, and would automatically press the brake or take whatever actions taking help of the stored memories. No conscious intervention is needed for those immediate reflex reactions. Here, the subconscious is automatically activated and guided by the emotional subjugative impact on 'fear' emotional scale.

All sudden reflex activities of subconscious are guided by emotional stresses. Like seeing another car in front, we automatically press on brake; watching a snake before us we reflexively jump back. All these are the activities of subconscious. Here, they are guided by sudden impact on 'fear' emotional scale. Visual memory subconsciously put subjugative threat on a particular emotional scale 'fear', and stress or pressure derived from it instantly direct further subconscious activities of 'house of intelligence' and 'house of physical activities'. These emotional pressures can lead to positive activity also. For example, seeing our beloved ones after a long time, we jump up in exhilaration. Here, subconscious activities are guided by upjugative pressure on 'love' emotional scale. When there is a threat on AR (adaptive range) for moving to negativeward direction, we act negatively to resist it, when there is a chance for AR to move to positiveward direction, we act positively to support it. Otherwise, a constant emotional pressure for moving AR from negativeward location to positiveward location on all emotion scales builds our general motivation. And our happiness is related with it. More the ARs move to positive direction, more we become happy. But our happiness could be differential in respect of different emotions. A person could be happy with all other emotions, but unhappy concerning a particular emotion if on that emotional scale AR is still sitting on negative location. Like that old fairy story - the king was happy in every ways, only grief was the king had no children (depleted in 'love' emotion). Again, our emotional house is leaking in nature. You will have to constantly serve it to keep the positions of the ARs towards positive ends.

But can subconscious be primed with any goal? Though, Bargh and his colleagues [Bargh et al., 2001] reported success in their experiments of high-performance goal priming, later many experimental works failed to replicate their findings, making their literature vulnerable to skepticisms [Harris et al., 2013; Shanks et al., 2013]. To explain and elaborate this issue, we will discuss it under next heading 'priming'. 


\section{Priming}

What is priming? Priming means that exposure to a particular stimulus may also influence a person's response to a subsequent stimulus without the person's any conscious application of efforts or intervention.

Now, priming is an example of implicit memory, or it is the work of the subconscious for retrieval of memory. Whenever we consciously recollect any memory or do anything that evokes our past memories, that retrieval affects our subsequent actions. This is true for actions of all of the houses, whether they are in conscious state or subconscious state.

Before going to deeper discussions, we will categorize memories a little bit. House of memory includes perceptual memories that is composed of memories of our past perceptions, and factual memories that encompasses all of our factual knowledge received through vision and audition. But besides these, house of memory also includes stored memories of activities of other houses. For example, we remember our emotional feelings, our intellectual activities (how we solved a math), and also physical memories (how to walk, ride a bicycle or play a guitar). From this perspective, we can categorize memories in four broad classes - (1) Informational memories (2) Intellectual memories (3) Emotional memories (4) Motor memories.

Informational memories can again be subclassified into two sections - (a) Factual memories, and (b) Perceptual memories.

Factual memory is composed of that which we receive as facts and concepts through vision and audition that constitute our general knowledge. Perceptual memories are composed of memories of our past perceptions which we receive through our different senses - like (i) visual memory, (ii) auditory memory, (iii) gustatory memory, (iv) olfactory memory, (v) tactile memory, (vi) proprioceptive memory.

Now, all these memories are connected with neural interconnections as already said all of the four houses are connected with each other through neural pathways. So, arousal of any informational or factual memory can also induce the arousal of an emotional memory. If someone once suffered and injured by 'fire', just visual exposure to the word 'fire', would also educe emotion 'fear' from memories of his past sufferings of pain by it. If someone is romantically related to one, just visual exposure to her name would flare up his romantic feelings associated with the name.

Even if, we were not exposed to something in past, yet we conceive new emotions from our general knowledge. For example, one even if never confronted with a 'tiger' before, would also conceive a weak emotional memory of 'fear' about tiger from factual memory i.e., general knowledge and concepts.

\section{Can some memories be hereditary?}

Every house of the mind can achieve some memories through the heredity of the organism. It is clearly visible if we watch behaviours of animals. We had pet dogs at our home - German 
Shepard and Spaniel. We brought them when they were only two or three weeks of age. After that, they seldom saw their own species. Yet when they grew up, they showed behaviours (way of sitting, greeting, waving tails, and many other minute and specific ones) that could be typically found in the same species anywhere in the world. They did not learn it through observations of their parents and other members in their species. It intrigued my mind how it is possible if some parts of our memory and subsequent behaviours are not hereditary.

This example asserts that some memories we receive through our genetical heritage. And it could be true for all types of memories, even emotional memories. Fear of water for cats is universal. We do not learn to walk watching how other walks. This motor memory expresses itself automatically as we grow up. In ethologist Konrad Lorenz's famous experiment with ducklings, ducklings followed Lorenz instead of their mother as they first saw him in a specific stage of development. But the instruction of following was hereditary.

Now, the arousal of any memory of a particular house as well as related or associated memories from other houses would all influence our subsequent actions, may it be conscious or subconscious. We call 'priming' when it occurs subconsciously.

It is noteworthy that arousal of a memory of a particular house by a stimulus also affects subsequent actions of that house. If one word is recollected, it becomes easier to subsequently recollect that word again or related other words. When we try to do a mathematics on a particular field after a long time that we learned very well, at first instance, it seems to be difficult, but in the following instances it becomes easier again. When we try to play a musical instrument after a long time when we learned it, initially we feel a bit awkward. But subsequently it becomes again fluent. All these examples relate the actions of a particular house. But the evoking of a memory of a particular house by a stimulus can also evoke a related memory from another house - that means recalling of any visual memory can also educe an associated emotional memory which similarly can influence subsequent actions of that house or other houses.

Bargh and Chen, in their famous series of experiments, showed that exposure of the participants in a specific way (e.g., scramble-sentence task) to some words related with particular concepts (e.g., rude, polite, old age), also modulated the subsequent behaviours of the participants [Bargh, Chen, \& Burrows, 1996]. Here the visual exposers to the words related to old age also induced weak emotional memories associated with those words. Those emotional memories (a kind of 'despair' - opposite of 'hope') were constructed based upon knowledge of facts and concepts. For that, this arousal of memories worked for not just recollection of related words, but also worked for their emotional feelings. And all collectively influenced their subsequent actions and behaviours; just like reading a ghost story, our mind becomes fearful, and that affects our subsequent actions also (we fear to go to toilet).

Now, we will come to the goal-oriented priming. Why many researchers failed to reproduce the positive results? Before that explanation, we will have to clarify what makes our goal or what directs our motivation. We will discuss it under the following heading. 


\section{What Makes Our Goal?}

All of our four houses of mind are guided by emotional drives as 'emotion' has been defined as "a specific sensation or feeling in the mind that provides directional drive to the other faculties of the mind - memory, intelligence, and physical activities - for their actions to be performed to pursue a specific goal" [Das, 2016]. This emotional drive comes from the pressure on an emotional scale (Fig.8) either from subjugation or upjugation, as our mind's goal is to move the adaptive range (AR) from its negativeward location towards positiveward location on an emotional scale or increase the mental status of the organism in respect of any emotional scale (consult emotional subjugation and upjugation in emotion model) [Das, 2016, 2017].

For example, we desire to eat when we feel hungry (i.e., subjugated on 'hunger' emotional scale). We desire to take revenge when we feel angry (subjugated on 'anger' emotional scale).

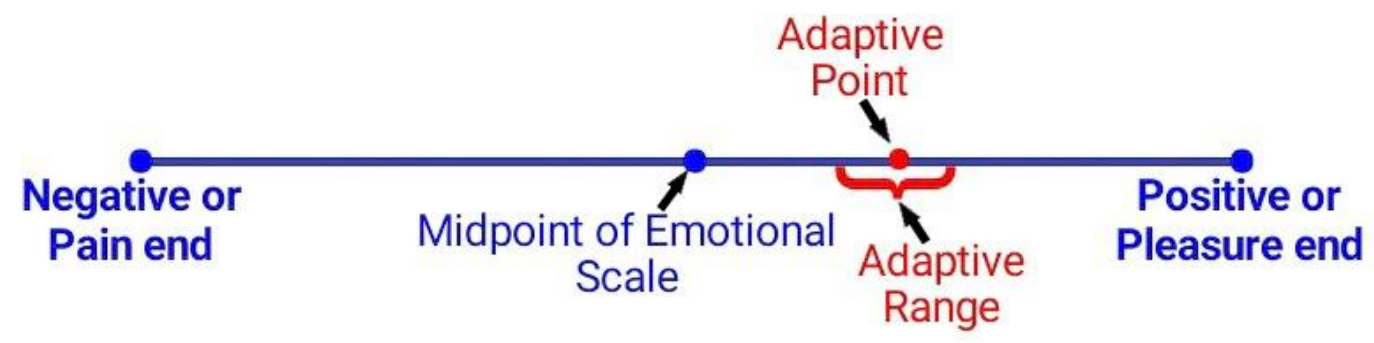

Fig. 8: An Emotional scale: The location of $A P$ and $A R$ is not fixed on an emotional scale. The tendency of AR to move from negative to positive direction establishes our goal (both conscious and subconscious) and designates the driving force of our entire life.

These emotional impulses created out of emotional stresses on different emotional scales drive all of our activities of four major houses of brain (memory, intelligence, emotion, and physical activities), and determine our conscious as well as subconscious desires and motivation. A person when hungry or subjugated on 'hunger' emotion scale, will desire to take food. When his hunger has been adequately satisfied there would be no desire till further subjugation occurs. Whenever you think of an interesting topic like as you are reading this article now, you are driven by your emotion 'curiosity' of your mind. Without it, you would not feel to read it, unless you are reading it for other purposes. This is true for all other emotions also. Emotional expression is also part of these activities (house of emotion), where emotional drives try to express it out to combat subjugative stresses. For example, someone took out his 'anger' on his spouse and got relieved. All these emotional stresses on different emotional scales collectively 
determine our desires, motivation and future activities. And this is true equally for both of our conscious and subconscious mind.

Our intellectual activities or logical thinking is not our primary goal. Many people live their lives relying on cultural and religious beliefs, or even on delusions (there is a question about existence of any demarcating boundary between those two). But does that matter? If your all emotions are adequately and regularly served, you are happy. Then why should you care for logical thinking, rationality. Our emotions are our goals; memory, intelligence and others are means to serve them. That is the difference between a computer and a human mind. In computer, there are no goals, only means.

\section{Now, how our conscious mind works?}

Our consciousness is like wandering flow of thoughts, thinking on one topic at one moment, again shifting to another topic in next moment. This stream is guided by two factors. One is emotional pressure; another is environmental stimuli.

(1) First, we will come to the emotional pressure. There are different emotions in our mind. And every moment, they are in different adaptive conditions. Depending on these adaptive conditions, emotional pressures are created. The adaptive ranges (AR) are not fixed locations on emotional scales. They are always changing their positions depending upon various emotional stimuli (derived both from present environmental stimuli and past unnaturalized emotional memories) acting upon that emotional scale for that moment [Das, 2016, 2017, 2018]. And the location of the AR on any emotional scale at any moment determines the emotional pressure at that moment. More the AR located towards negative side; more emotional pressure would be produced by that emotional scale.

Our conscious thought is primarily guided by these emotional pressures. For example, A hungry person would try to think about getting food. His 'hunger' being satisfied, he would switch his thinking to other issues propelled by other emotional pressures for example, his 'hunger' being satisfied, he will seek for sexual pleasure to satisfy his sexual emotion. His 'sexual emotion' being satisfied, he will read 'The Chariots of God' to satisfy his 'curiosity' emotion. His 'curiosity' being satisfied, he will watch 'Modern Times' to satisfy his 'humor' passion. His 'humor' being satisfied, he will feel the pangs of 'hunger' again. And these go on throughout the life. But serving of emotions depends on availability of the situations. If the situation is not available, or does not permit for some emotional satisfaction, the person will be deprived regarding that emotion. As already stated, in subjugated state on any emotion, the person becomes adapted and does not feel any distress, yet he will feel some kind of unhappiness regarding that emotion. So, we had to constantly serve our every emotion to make us happy, because our upjugated state on every emotion does not persist for long time, or it could be said our emotions are leaking in nature. 
If we go very deep, then we will see this gradual shifting of adaptive ranges (ARs) is actually due to weakening of upjugative or subjugative emotional memories to be effective on an emotional scale that has been described in my article (Das, 2018b). So, in such ways, our conscious thinking is driven by different emotions - 'love', 'anger', 'fear', 'utsaha'. But the seriality of conscious thoughts is not always concomitant with severity of emotional pressures. Environmental stimuli or contexts play a great role in case of conscious thinking. And that would come as a second guiding factor.

(2) If one introspects, he would find that he does not think the same way when he is in a family or friends gathering and when he is alone in an isolated room. When environmental stimuli act upon, conscious thinking becomes prone to be influenced by them to a certain extent disregarding the seriality of severity of different emotional pressures. But whenever environmental stimuli are absent or minimal, the severity of emotional pressures start to act upon. For example, any humorous and buoyant family or friends gathering may divert a person's thought about any underlying severe worry or 'fear'. But whenever the person gets alone, the thought about his 'fear' recurs to him.

Moreover, conscious mind takes into account the availability of the situation to serve emotional pressures or fulfill wishes, can adjust activities for future better gratifications of them, and to a certain extent, suppress or compromise with its desire considering social and moral obligations. For example, someone is hungry and he sees there is a shop where low quality meal is being served. But he knows that if he could take few steps ahead, there is another shop where high quality meal is available at the same price. In this case, his conscious mind would delay his desire's being fulfilled for better gratification. If anybody is angry on someone, but the situation says that it is not wise to express his 'anger', he would consciously inhibit his desire for future fulfillment. However, here should be added that delaying of emotional pressure, can initiate adaptation procedure. For example, if someone neglects his 'hunger' for a time, after a time, he would feel reduced hunger. However, as 'hunger' has perceptional stimuli coming from hypothalamic receptors that would act continuously, it is more prominent in case of other emotions (for details, see Das, 2016, 2017).

\section{Now we will come to how subconscious' activity is different from conscious thought or activity.}

(1) The primary drive of conscious mind is equally applicable to subconscious mind. Emotional pressures act on in the same way as they act on in conscious mind. But subconscious is less inhibited by the environmental contexts. Our conscious mind, without neglecting the emotional stress, can emotionally neutrally assess the future outcome, and adjust activities. Subconscious' activities are devoid of these features, and though environmental contexts modify our conscious activities, our subconscious relentlessly works upon our emotional stresses. As already said, a 
humorous or buoyant friends or family gathering can obliviate many underlying severe stresses of ours. But the subconscious remains active on those. Whenever the person is alone, relaxed, or in sleep, subconscious resurfaces with its processed products of activities to consciousness through intuitions, emotional urges or expressions, sudden retrieval of memories, or through dreams in sleep (though in surreal ways). Usually, strong environmental stimuli inhibit resurfacing of subconscious' activities into consciousness. Whenever environmental stimuli are absent or minimal, that means the person is alone or in relaxed condition, there is a greater chance of subconscious' resurfacing or projecting of its activities into our conscious mind.

However, environmental stimuli can act on subconscious only, when those stimuli also exert great emotional impact, and create new emotional pressures; like jump back in fear watching a snake, or jump in exhilaration seeing someone beloved. In those cases, conscious mind does not give order to act in that way.

Our conscious and subconscious goals are not fixed. It depends on the severity of emotional pressures. A malnourished child of a poor family would do many things to get some food either consciously or subconsciously, a well-fed child of a rich family would not. When one emotion is adequately satisfied on continual basis, our goal (both conscious \& subconscious) also changes with regard to that emotion. Some literatures have argued [Shiffrin \& Dumais, 1981; Schneider \& Fisk, 1982] that specific situations or stimuli, strengthened through consistent encounters, can initiate automatic subconscious processing and engender our subconscious goals. But it is not completely true. It is acceptable to some extent that consistent training makes any of our mental processes regarding certain stimuli easier and improved in functioning. But emotional charges play a great role for it. An enthusiastic and motivated student would learn many things even through single exposure. A nonenthusiastic, unmotivated student would find difficulty in learning even after repeated trainings. In Schneider \& Fisk's experiment, they selected target stimuli as upper-case letters from English alphabet, which were emotionally neutral. So, they found expected result.

In case of retrieval of that mental function either consciously or subconsciously, or in automatic initiation of subconscious processes, it is not just the consistency of the stimulus, but how the stimulus would relate to the then concomitant emotional pressures of mind, is also important. In a hungry or thirsty state, we would be caught by the sight of food or water more intently (consider the experiment by Strahan) [Strahan, 2002].

When we choose to fix consciously a long-term goal (like becoming a doctor, or lawyer, or film star), we assume that reaching that goal would give us the chance to better serve our emotional desires. And this positive thinking elevates our 'mood' or energy level of mind ('mood' is different from 'emotions', for details see Das 
2016, 2017, 2018). This hunch equally works for our subconscious activities also. And we work with elevated energy level or elated 'mood' towards that target. But the drive comes from emotional desirous pressures acting behind. When we conceive that reaching that target would not satisfy our emotional desires (like, doctors are now very poorly paid, and socially disregarded), that negative thinking depresses our 'mood' or energy level of mind and we experience a feel from elation to depression.

(2) Some memories we can consciously retrieve. But there are many memories in our mind that we cannot consciously retrieve though their impressions are still there in our mind. When we consciously try to do something (like to recollect memories, to solve any problem, to decide future activities), we can take only those memories that are retrievable. On the other hand, our subconscious mind to do the same activities can take help of the fairly fainter irretrievable memories also, and can project its processed products into consciousness through intuition, sudden retrieval of memory, dreams, etc. For example, in case of intuition, the solution suddenly flashes in our mind, or intuition tells us to avoid something. But we fail often to recognize how the solution flashed or why the urge for avoidance is. Whenever we consciously try to do something, we engage concurrently our subconscious also, only we are not aware of its undercurrent activities till its processed products resurface to our conscious mind.

(3) Sometimes, our conscious activities are guided by socially imposed moral obligations, taught principles etc. And we subdue our desires to a certain extent because of those. Our subconscious activities are less propelled by such moral obligations or preaching, if not these obligations impose threat or reward, i.e., pressure on emotional scales. From that perspective, we can say our subconscious is less moral than our conscious mind. In dreams, drunken state, or in many medical conditions, where consciousness becomes clouded or blunted, we do talk or behave like such that we would not have done if we were in fully conscious state.

(4) In nutshell, both of our subconscious and our conscious mind are very closely related and works hand in hand, as both are the same activities of our four houses of mind. Difference is the activities of subconscious involve wider area of inner mind talking account of both consciously retrievable and irretrievable memories. Whereas, our conscious mind takes into account the present surrounding situations and concurrent environmental or sensory stimuli to adjust and compromise with their activities. Subconscious gets only affected by environmental or sensory stimuli, when they impose emotional pressure, either subjugative or upjugative. So, it could be said, our subconscious mind takes more care of our inner world of mind and our conscious mind take more care of our outer world. 


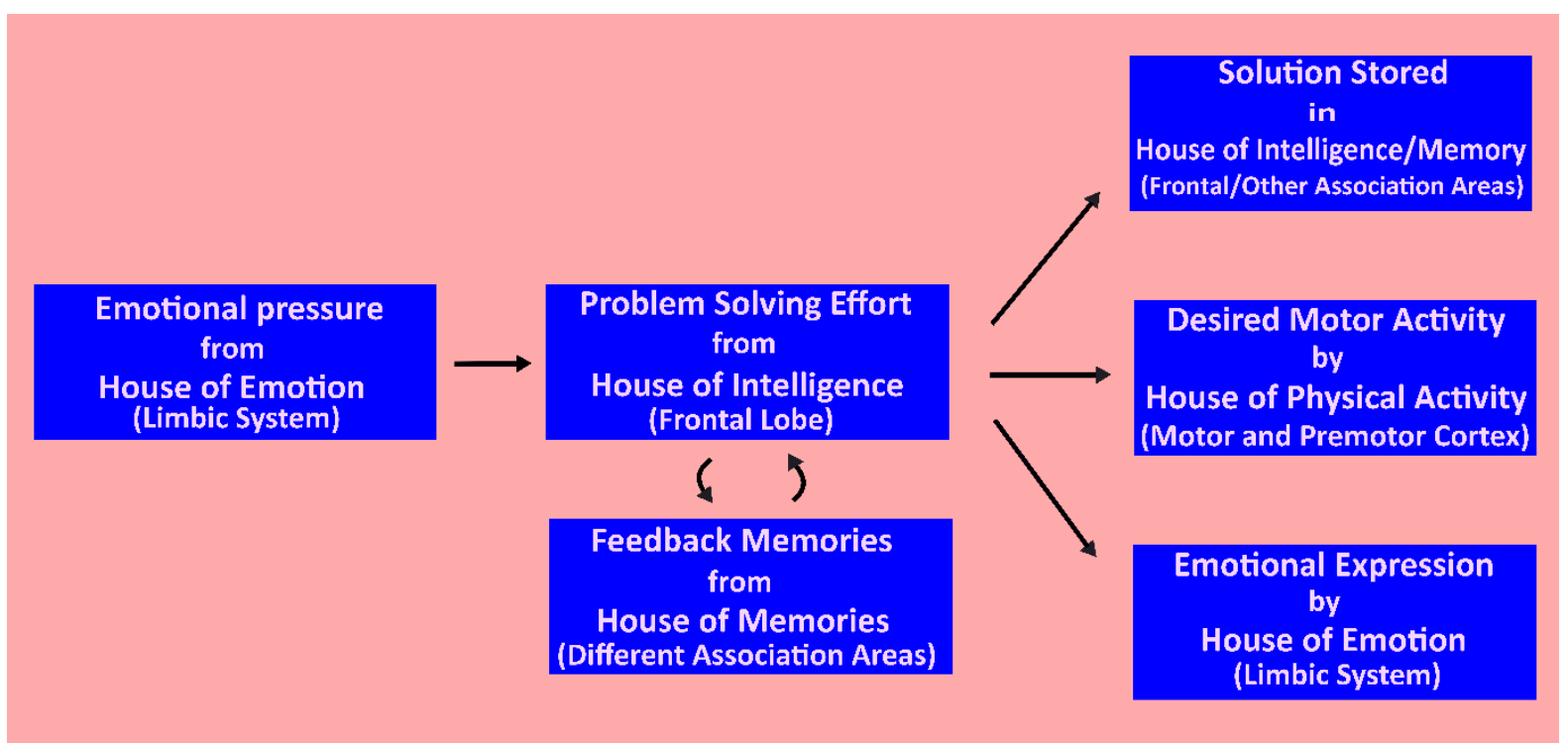

Fig. 9: Mechanisms of Activity guided by Primary Drive in both Conscious and Subconscious Mind

So, emotional stresses on different emotional scales drive and determine equally both of our conscious and subconscious desires, motivation and future activities (Fig.9); but conscious mind can adjust this drive considering the concurrent environment or surrounding situations and compromise to a certain extent with social and moral obligations, whereas our subconscious is less judgmental and less moral. But the ultimate goal of both is to derive the greatest fulfillment of emotional desires out of life. Generally speaking, these emotional stresses for moving AR from negative to positive entity on different emotional scales actually direct all of our conscious and subconscious activities of brain as well as our entire active life.

Our conscious and subconscious mind has influences on our unconscious activities of brain also as explained earlier, but the emotional stresses or drives do not directly influence the unconscious activities of brain. Like, urges for defecation and micturition, visceral pain, heart rate and breath rate, cerebellar maintenance of posture and balance are not dependent on emotional drives. But their activities can be modulated by conscious and subconscious activities of four houses of mind, and thus they are indirectly dependent on emotional pressures through the activities of conscious and subconscious mind.

Now, I will come to a serious question. Is it possible for our mind (either subconscious or conscious) to deny our emotional drives or pressures?

To answer this, I should say we all in our civilized world live with some subjugations coming from different quarters, and subsequent adjustments or adaptations. We cannot expect the adaptive ranges (AR) on all of our emotional scales will stand on the extreme positive point. That would throw us in a state or condition of extreme happiness with regards to all emotions. 
And I also doubted in my previous articles whether the tendency of AR is to move from negativeward to positiveward location or it is to move towards the center. Because in case of physical perceptions we see, we do not like too much hot condition or too much cold condition, but between the two - to an optimum condition. So is true for lights, sounds, pressure. Adaptational processes for emotions and perceptions are not too much different in that sense. In case of both, if we are forced to stay on some points of their scales, we gradually get adapted with those points and when the AR resettles their location, we do not feel any more sense from that. So, when we are forced to stay in hot climate or noisy surroundings, we gradually perfectly fit with those and after a time, we do not feel any distress. Similar things happen with emotions. We can adapt with a subjugative state. If we work in an office, we will have to be subjugated to our higher authorities on 'fear' emotion scale. We all units of social beings are subjugated on different emotions in different degrees in different arenas of social world. We fear the law, we fear the police, we fear the gangsters. For that, ARs on all of our emotional scales cannot stay on far positiveward locations. But the difference between perceptions and emotions is that the subjugated location of AR on any emotional scale produce an underlying sense of unfulfillment that leads to a feeling of unhappiness. A person perfectly adapted to a hot climate, may not feel any desire to migrate to a cold climate. We do not feel normal barometric pressure, but for that we do not show any desire to move to a place where the pressure is less. But, though an emotionally subjugated mind at adapted state where AR has been completely relocated would not feel any emotional destress, yet it would feel a sense of unhappiness towards life. Happiness or higher mental status (both are synonymous) is directly proportional to the locations of the ARs towards the positive extremities of the emotional scales.

Now the initial question was - 'Is it possible for our mind (subconscious or conscious) to deny the emotional drives or desires?' We can deny consciously our emotional drives and that would initiate subconscious adaptational processes, eventually making us indifferent (not feeling any distress) towards the situation. But if we ask introspectively 'are we perfectly happy?', the answer would be most probably 'no'. Through denial, we can get stability, but it will incur some kind of unhappiness. So, to my view, it is better to adopt emotional control than emotional denial. Again, over-happiness not all the time ensures subjective well-being. A person will feel most emotionally stable and sufficient when his ARs would locate on the midpoints of all emotional scales and fluctuate a little towards both sides of that point.

So, sometimes it is wise to say to your mind 'Go there', Enjoy yourself', but not all the time. Don't eat all the time whatever you like or whatever you wish. But eat balanced food at specified time. These are good for your mental as well as physical well-being. This superconsciousness is least prominent in animals; they are mainly guided by the primary drives. Even in human, it is not equally dominant among all. I would not divide conscious mind into another compartment of superconsciousness, but I would say it is just the higher form of consciousness. Our conscious experience when we enjoy some movie or devour some tasty food is one form of consciousness. But whether we should watch that movie or discreetly think about whether the food is healthy or not is another form of consciousness at a step higher. However, the ultimate goal of our mind whether it is subconscious or conscious, is to serve our 
all emotions adequately and sufficiently to attain sustained happiness in our life. And that effort leads our life.

Also, I should add that this superconsciousness though minimal in animals, yet is not altogether absent in them. A cat from my adjacent house was disturbing greatly, stealing foods from kitchen. So, I put some poisonous powder inside a fresh fish and I put it on the way of it. The cat when saw it, it smelled it, showed some features of suspicions in mind, and left. It did not eat it.

So, here superconsciousness means intellectually guided emotional gratifications, not denial of emotional pressures or emotional gratifications. But why did this superconsciousness develop? Obviously for its evolutionary advantage. An organism with superconscious mind would live longer and achieve more success.

Now, what happens to goal-oriented priming?

In high-performance goal-oriented priming experiment, Bargh et al. used words like 'win', 'compete', 'succeed', 'master' etc. to prime the subjects. But do these words arouse any emotions of us? - Possibly not. Our positive thinking cannot be forcibly induced. Positive thinking depends on our thoughts conceiving the fact that there is possibility of gratification of our emotional desires. If our mind cannot conceive that fact itself; it also cannot do positive thinking. It could be done through persuasion. For that, gurus, mentors, self-help literature are so popular. But without that, just visual exposure to the word 'success' cannot induce positive thinking or create elevated 'mood' in a mind. ${ }^{4}$

But if we feed our mind with such information that are emotionally related, or will help our concurrent subjective emotional goals or stresses, the subconscious activities will be certainly guided by them. Theses emotional goals or stresses are both person-specific and time-specific. A person may have some emotion with greater magnitude; but his emotional stress could be neutral, or less, or great depending upon on what position of emotional scale his adaptive range (AR) is lying in a particular moment [Das, 2016, 2017]. And the emotional stress of that emotion of that particular time will guide our subconscious mind accordingly for that moment.

Have you ever experienced that when you had been very hungry but slept, you saw the dreams of food, but not in the case when you slept in well-fed state? Dream is projection of subconscious' activity on conscious mind. So, a depressed mind's goal cannot be primed with a positive word without persuasion, and that raised the question for the success of goal-oriented priming.

Goal-oriented priming is possible only with emotionally related stimuli, and of course, if there is emotional pressure in mind in that direction at that moment. If you have a strong desire to do something, like writing this article for me, just feed your mind with necessary information the mind will automatically and subconsciously work upon it.

\section{How Subconscious Influences Our Attitude, Behaviours, and Personality?}


"Every work that we do, every movement of the body, every thought that we think, leaves such an impression on the mind-stuff, and even when such impressions are not obvious on the surface, they are sufficiently strong to work beneath the surface, subconsciously. What we are every moment is determined by the sum total of these impressions on the mind. What I am just at this moment is the effect of the sum total of all the impressions of my past life. This is really what is meant by character; each man's character is determined by the sum total of these impressions. If good impressions prevail, the character becomes good; if bad, it becomes bad."

- Swami Vivekananda [Vivekananda, 1896]

Swami Vivekananda was a spiritual leader, and this article is pursued based on naked science, leaving no space for spirituality. Yet his above-mentioned words have much truth than anyone else's.

What makes our personality? It has been discussed in details in the book [Das, 2016], and the article [Das, 2017]. I will briefly enumerate that here.

As already said, our behaviours are guided by the emotional pressures. But how these emotional pressures are exerted? The same emotional stimulus makes a person angry but may not make other. And that differentiates the personalities of the two. But why same emotional stimulus affects differentially different persons? It depends on the position of AR (adaptive range) on that person's that particular emotional scale. Any stimulus evoking on the negative side of the AR would evoke negative response (e.g., the person would be angry), and if it evokes on the positive side of the AR, the person would be satisfied. If it evokes response within AR or adaptive range, the person would remain neutral.

Now, how is this position of AR determined on different emotional scales? It depends on our unnaturalized emotional memories. Memories of different types have already been described earlier in this article. Of all memories, only emotional memories determine the position of AR. Many factual memories in our lives are associated with emotional memories like feelings of first dating, feelings of some beloved one's death. The difference between factual memory and emotional memory is on repeated recollections, factual memory gets stronger but the emotional memory becomes weaker. The reason is at each recollection the subject expresses out some of the emotion. So, in subsequent recollection, a person feels lesser degree of emotion. And after a number of recollections, the emotional memory virtually dies out.

Now, all the emotional memories of different strengths of a particular emotion either positive or negative ultimately fix the position of AR or adaptive range on that emotion's scale. And with respect to these ARs on different emotional scales, a person's behaviours and attitudes are discerned when new emotional stimulus is inflected on him. And as a whole, this builds the personality that we hold.

But here it must be added that genetical heritage of emotions is also important. If one does not possess an emotion at all, or possesses an emotion with minute magnitude, emotional pressure created by it will also be of lesser magnitude. 
According to Sigmund Freud, the 'unconscious' is a dynamic system. Its contents and processes are kept from conscious awareness through the force of censorship or repression of instinctual drives which are primarily the derivatives of sexual instincts. The unconscious activity is guided by the 'primary process thinking' aimed at fulfillment of wishes and governed by pleasure principle. It lacks logical connections and denies the existence of negatives. It is unnecessary to say how close Freud grasped the true essence of unconscious more than a century ago.

But there are some flaws in his theory of unconscious.

(1) Freud's tendency to orient present behavioral or personality problems with hidden sexual thoughts in childhood is not proper. 'Sex' is just one of the emotions. And it is also not a complete emotion. Like 'hunger', 'thirst' it is also half-emotion and halfperception. 'Hunger', 'thirst', 'sex', have both features of an 'emotion' and 'sensory perception' [Das, 2016, 2017]. Whatever it is, any particular emotion cannot determine our present personality, it depends on aggregation of impulses from all the emotions.

(2) Freud's theory particularly emphasizes on memories suppressed in distant past or childhood. But any emotional memory whether it is stored unnaturalized in distant past or it is stored moments ago, would equally affect our behaviours and personality. How they would affect that depends on their strength rather than the time of their being stored. As already said, with repeated recollections, emotional memory dies out little by little because with each recollection, it expresses out some of its emotions. And after a time of repeated recollections, only the factual memory will stay there in the mind, but associated emotional memory will be lost.

For example, if you were greatly shocked at the loss of your romantic partner, or at the death of someone beloved of yours, and after that you repeatedly recollected those, your emotional feelings would gradually be diminished. And after a time, you would remember only the fact of loss of them, but would not feel the associated emotions. Besides repeated recollections, emotional memories also die out over time because of subconscious expression of emotions.

So, there is less chance of memories repressed in distant past compared to recent ones to affect your present personality and behaviours. You would not be the same person as you were in your childhood, if there are lots of ups and downs and many changes of surroundings in your life. Any major emotional impact would change you a little to make you a bit different person from your previous self.

(3) Freud also did not differentiate the types of memories. It is not the factual memory but the emotional memory that determines our attitude and behaviours. But the factual memories help in other ways. For example, if you see a tiger in front of you, you will be greatly afraid. Here no past emotional memory is involved unless you fought with a tiger in past and won against it. The knowledge about a tiger what it can do to you would create new emotion of fear within you. Again, if you see it in a cage in the zoo, 
you would not be afraid at all. Here also your knowledge that it has not the power to break the iron bars of cage, keeps you indifferent.

(4) Freud differentiated between primary and secondary process thinking as the features of unconscious and conscious mind respectively. According to him, primary process disregards logical connections and existence of negatives. But in true sense, there are not many differences between our subconscious and conscious thinking as they are conducted by the same areas of brain. They both follow logical connections and abide by existence of negatives. Practically, emotional pressures by whose direction the subconscious (and also the conscious) mind acts are determined by the positions of ARs (adaptive ranges) on emotional scales. And this position is fixed by both positive and negative impulses acting on the emotional scales. Only difference is conscious mind can adjust their activities considering the concurrent environmental context, and to a certain extent, inhibit its desirous activities against social and moral obligations. Subconscious' desirous activities can also be checked by morality, if they pose with threat or reward.

Yet, accepting all these flaws, Freud's concept of unconscious mind and its recesses of repressed thoughts, desires, and memories more than a century ago has always stood as a lighthouse to direct the curious perusal of under-covered mind by the academics of following generations.

\section{Can Subconscious Perceive Subliminal Stimuli?}

By definition, subconscious cannot perceive any stimuli. Every moment hundreds of stimuli are impinging on our different senses (visual, auditory, olfactory, gustatory, tactile, proprioceptory). But we consciously perceive those stimuli which we give our attention to. We pay attention to those stimuli depending upon either its severity of strength or for other reasons. It is not the fact that the strongest stimulus we will perceive the first. It goes also with our intention derived from our emotional pressures or wants. Even in loud noise, we can read an interesting book.

So, the meaning of 'subliminal' here becomes confusing. What should we call 'subliminal'? The stimuli whose strength is so low that it cannot be perceived by the conscious mind or the stimuli that we do not pay attention to through our conscious mind?

Regarding the strength of the stimuli, the concept of objective and subjective threshold had been postulated [Cheesman \& Merikle, 1986]. An objective threshold is such that a stimulus with strength greater than it can be perceived by our sensory system. A subjective threshold is such that a stimulus with strength greater than it can be perceived by or can enter into our conscious mind. So, the minimum strength of a stimulus required for our conscious perception is greater than that of subconscious perception. Is it so? Can we perceive weaker stimuli subconsciously? It has been a matter of hot debate for many years [Dijksterhuis et al., 2005]. 
But the matter is if we can perceive subconsciously, then that information should also have effects on houses (memory, intelligence, emotions, etc.) or other systems of mind. Because without having any effects on mind system, it would be equivalent to non-perception. And as already described that all the houses are being run subconsciously also, with that new information, we can learn new things without paying attention to it at all. This means that just by holding the pages of mathematics book in front of our eyes, but without paying any conscious attention to it, we can learn mathematics. This is a bit difficult for accepting.

Some success in support of subliminal perception has been claimed in experiments with dichotic listening [Deutsch \& Deutsch, 1963; Carr \& Bacharach, 1976; Duncan, 1980] and parafoveal vision [Willows \& MacKinnon, 1973; Bradshaw, 1974; Underwood, 1976]. For details, see Holender, 1986. Here it should be noteworthy that our every perceptual feeling is not just composed of a single data. Our perceptual feelings (visual, auditory, etc.) are focusattended integrated perceptual feelings. In case of visual feelings, there is anatomically defined foveal region for focus attention and para-foveal regions for gradually minimal attention. As a whole, we make an integrated visual feeling every moment with maximally attended focal region. But other regions of the field are not altogether unattended. Again, our visual feeling at any moment is not entirely made up of reality. A part of this integrated feeling is also made up of memories from our past experiences and that is the mystery behind the generation of illusions (optical and others). Only 10-20\% of the inputs to the lateral geniculate nucleus comes from retina, other inputs come from other regions of the brain including feedback inputs from the visual cortex. In visual cortex, the number of neurons concerned with vision is 1000 times the number of fibers in the optic nerve [Ganong, 2019]. For details, see my previous literature [Das, 2018a, 2021]. In case of other perceptions rather than visual, there are no anatomically defined focal regions; yet, we attend somewhere maximally. When we listen to a music, we can also faintly feel consciously the sound of rotating fan above head. In case of dichotic listening, though we attend one ear, yet sounds in another ear is not completely unattended consciously. And we change our focus whenever there occurs anything significant in our minimally attended field. In the dichotic listening situation, research participants have diverted their attention to the unattended ear if their own names were uttered into the unattended ear [Moray, 1959]. So, success in support of subliminal perception in these experiments is little inexplicit. It is not the fact that unattended ear or parafoveal field of vision are altogether consciously unattended.

Another point to be cleared that there are also successes in experiments with subliminal priming. Here, the most important thing to be noteworthy is that our subconscious cannot perceive, but all of our houses (memory, intelligence, etc.) are run subconsciously also. So, these houses can always work subconsciously with perceptual memories or information that has been gathered consciously already, even moments earlier; and they can produce their products to consciousness as intuitions, sudden retrieval of memories, etc. Many may mistake these rapid subconscious processings of the houses of mind are involved with subliminal perception. But subconscious can only work with stored memories and that which have been perceived consciously even moments before. Subconscious itself cannot perceive through any senses. For that conscious attention, even with lowest gradient, is required. So, this process 
should not direct us to the erroneous notion that perception could be done subconsciously or subliminally.

Holender argued that if we do not pay enough attention to a stimulus, we will soon forget about it. That does not imply that the stimulus was perceived subconsciously. He states semantic activation is usually accompanied by conscious identification [Holender, 1986]. We support his view. Whenever a stimulus is perceived, it affects the houses of mind, memory, intelligence, emotions etc., and further processing of the meaning of the stimulus and its effects on the mind system is decided. Now, if that stimulus is paid minimal conscious attention according to the concomitant emotional drives, and it has minimal importance for our emotional goals decided by our houses of mind, it would be kept in memory for a very short period of time, and we may not retrieve it consciously thereafter. But if it has greater importance, we learn new things that is kept in memory for variable times.

Sometimes, some weakly potentiated perceptual information in memory, after a time, may be unable to be retrieved consciously, but these weaker memories can be used in subconscious' activities up to a certain strength of the memory. It often occurs when we find the answer behind tongue. We cannot clearly retrieve the memory, but can feel its effects on mind.

However, our conscious perception is not just depended on the strength of stimuli, but far more it is depended upon emotional driving pressures through which we pay our particular attention to. A hungry person would notice the view of food, not a full-fed person. So, a stimulus with a particular strength one time may enter our consciousness and other time may not.

Again, our conscious attentions in different quarters, as already described earlier, are not always similar in intensities parallelly. When you are driving a car with another thought, your visual feelings of the streets are not at the same level as when you watch a movie. When you are reading a book intently, your visual perceptions of the words of the book are minimally conscious. We may make mistakes by regarding these minimally conscious perceptions as subconscious perceptions.

Strahan et. al conducted some studies on subliminal priming and persuasion. One set of studies was to examine whether beverage choices could be influenced by brief exposure to thirst related words [Strahan, 2002]. In their experiment, the participants were asked to look intently on the screen where words were flashed for 16 milliseconds. Afterwards, it was found the subjects who were shown thirst related words, chose thirst-quenching beverage more, whereas the control group preferred to choose the other option more. In this study, the visual stimuli were not that weak that our conscious mind cannot perceive. Instead, visual stimuli were such that our conscious mind would differentially pay attention to them.

As already said, if we pay brief attention to stimuli which are not of great worth for attention, we soon forget about those stimuli, sending memories of them to the irretrievable vault of the memory storage. Later on, our conscious mind cannot retrieve them and cannot take them in consideration for their activities. However, our subconscious mind can take these consciously irretrievable memories out if they are still there present in the storage, and can involve them in carrying out its subconscious activities. And that is what actually happened in that experiment. 
Our subconscious activities are depended on memories, and can use memories that are weak to a certain extent, and consciously irretrievable.

There is another outcome of this set of experiments that further asserts this explanation. The influence of the subliminal persuasion was found particularly among the subjects of the test group, those reported being thirsty before the start of the experiment. So, emotional subjugative pressure on 'thirst' was working on their mind, leading to emotion driven differential conscious perceptions followed by subconscious activity for preference of beverage.

\section{Subconscious in Sleep:}

In sleep, conscious activities of perceptual quarters as well as houses of memory, intelligence, emotions, and physical activities are stopped. New information gathering, intellectual efforts, or voluntary muscular activities do not happen in sleep. But though in this stage all activities of our conscious mind stop, our subconscious remains awake. On the contrary, it is the time for the highest activity of our subconscious mind.

Subconscious process of memorization of important information, long term memory potentiation, intellectualization of recent experiences, emotional expressions and adaptations, all run on in sleep.

Subconscious also acts in wakeful state, but it is less active then than in sleep. For that, sleep is so much necessary for higher evolved brain, where a significant factor for survival depends on the higher brain functioning pivoting on experience, knowledge and learning.

In sleep, subconscious reframes our mind by analyzing recent experiences, newer data; potentiating newer memories; expressing out some emotions; and others. Dreams occur usually in 'REM' stage of sleep. Though dreams are always not easily interpretable, but they occur in shallow stage of sleep, rather than deep stage. To be precise, they occur just in the previous stage of wakefulness before awakening from the sleep, where subconscious merges with the conscious mind to act as a backstage of the conscious mind in the wakeful state. So, dreams are actually the projection of subconscious' product, or outcome of works into the awakening conscious mind.

When a person sees a dreadful dream, then he must know that there in his mind are stress factors, which were masked under in his conscious state. But dreams do not represent the proper frame of these stress factors, instead takes a surreal route. The reason behind it could be some improper functioning in integration of conscious and subconscious mind that occurs when a person is in sleep state, particularly just before awakening, when consciousness begins to gradually come into its usual existence.

In our conscious life, we are involved in so many activities and attached emotionally with so many relations, that we often forget or remain indifferent to many factors that eventually may be harmful for our existence. A good joke, or buoyant friends or family gathering may obliviate many matters of worry for a time. But those remain latent in subconscious. In sleep 
subconscious resurfaces them, assesses them, judges their gravity on the pretext of the present situation, and sometimes, projects them in dreams. Emotional expressions also occur in a great degree in sleep through subconscious activity. For that, besides dreams, after a good sleep, we feel fresh with new hope, can think of new possibilities, new ideas and new strategies. In sleep the subconscious sets the mind on right track, detects masked factors that should be corrected, facilitates emotional expressions of harmful emotional experiences, potentiates useful memories; and gives hints for future activities through intellectual work-up when it resurfaces into consciousness in awaken state.

In one sentence, subconscious' activity in sleep is essential for higher functioning of the highly developed brain.

\section{How Much Is Our Subconscious Reliable?}

Subconscious' activities with respect to memory, intelligence and physical activities is indispensable for higher functioning of brain. With respect to emotional urges, our subconscious' instincts are also very essential for our survival. In too many acute exigencies, we act on our immediate instincts, rather than by planningly thought out actions of our conscious mind. These types of actions are more prevalent in animals who are mainly guided by subconscious' instincts, rather than conscious decisions. But the fact is in human civilization in various situations our mind's subconscious urges to actions are not always justified morally or acceptable socially. In this regard, man, being a moral animal, lies on a step behind the animals who are predominantly guided by the animals' subconscious instincts or simply animal's instincts rather than moral obligations. So, to consider our behaviours and actions, we should know that in one hand, subconscious' urges or instincts are devoid of moral obligations, thus it is less biased and more accurate than our conscious decisions. But on the other hand, subconscious can misdirect us which occurs in severe emotional subjugations - like obsessions, addictions, and seductions - to take harmful activities because as already said subconscious' activities are maintained by the subjugative stresses on different emotional scales, not abiding by concurrent moral or social surroundings if not they do pose threat or reward for any emotion. Not only that, 'subconscious' is also unable to emotionally neutrally assess the possibility of future outcome, whether it would be better or worse. And thus, it is incapable of direct itself by goal-oriented-wise decision making. So, in those situations, subconscious can misdirect the person with urges for actions incurring future catastrophes and even self-danger. So, considering subconscious' urges, there are both positive and negative aspects, and that should be weighed and justified by an intellectual mind as is the case of a human mind. But for that, a person should have proper knowledge and power of introspection in a correct manner.

\section{Conclusion:}

This article has described the nature and functions of our conscious and subconscious mind. There are lots of myths about our conscious and subconscious mind. Proper scientific 
approaches and experimental works will only disclose the truth and give us precise knowledge to explain our minds, rather than believing in myths. 


\section{References:}

1. Baars B J (1988). A cognitive theory of consciousness; 1988, NY: Cambridge University Press.

2. Bargh J A, Chen M, Burrows L (1996). "Automaticity of Social Behaviour: Direct Effects of Trait Construct and Stereotype Activation on Action". Journal of Personality and Social Psychology; 1996, 71(2): 230-244.

3. Bargh J A, Gollwitzer P M, Lee-Chai A, Barndollar K, Trötschel R (2001). "The automated will: nonconscious activation and pursuit of behavioral goals". Journal of Personality and Social Psychology; 2001 Dec, 81(6): 1014-27.

4. Bartolomeo P, D'erme P, Perri R, Gainotti G (1998). "Perception and action in hemispatial neglect”. Neuropsychologia; 1998, 36(3): 227-237.

5. Basant A, Das B (1905). The Bhagavad Gita; 1905, London \& Benares: Theosophical Publishing Society.

6. Behrmann M, Ebert P, Black S E (2004). "Hemispatial Neglect and Visual Search: A Large Scale Analysis". Cortex; 2004, 40: 247-263.

7. Bisiach E \& Luzzatti C (1978). "Unilateral neglect of representational space". Cortex; 14, $129-133$

8. Blackmore S \& Troscianko E T (2018). Consciousness: An Introduction. 3rd Ed, 2018; London \& NY: Routledge.

9. Bradshaw J L (1974). "Peripherally presented and unreported words may bias the perceived meaning of a centrally fixated homograph". Journal of Experimental Psychology; 103(6): 1200-1202.

10. Buxbaum L J (2006). "On the right (and left) track: Twenty years of progress in studying hemispatial neglect. Cognitive Neuropsychology; 2006, 23(1): 184-201.

11. Carr T H, Bacharach V R (1976). "Perceptual tuning and conscious attention: Systems of input regulation in visual information processing”. Cognition; 4(3): 281-302.

12. Chalmers D J (1996). The Conscious Mind: In Search of a Fundamental Theory. 1996; New York: Oxford University Press.

13. Cheesman J, Merikle P M (1986). "Distinguishing conscious from unconscious perceptual processes”. Canadian Journal of Psychology; 40: 343-367. 
14. Das K (2016). MIND: A Comprehensive Study on Mind and Its Dynamics. February, 2016; Kolkata: K P Basu Publishing Co. ISBN-13: 978-1539394396. (https://www.amazon.com/Mind-Comprehensive-Study-Its-Dynamics/B01M20Y9ON).

15. Das K K (2017). "A Theoretical Approach to Define and Analyze Emotions". International Journal of Emergency Mental Health; 19(4): 374, 1-14.

16. Das K K (2018a). "Role of pre-embedded associated memory in generation of optical illusions". Journal of psychology and cognition; 2018, 3(2), 37-49.

17. Das K K (2018b). "Therapeutic Reprocessing of Association of Memories (TRAM)". International Journal of Emergency Mental Health; 20(2): 376, 1-7.

18. Das K K (2021). "Hermann Grid Optical Illusion and The Rebelling Dots of Reality". International Journal of Scientific and Research Publications (IJSRP) 11(4):428; April, 2021, 11(4): 428-440.

19. Dennett D (1991). Consciousness Explained; 1993, Penguin Books.

20. Deutsch J A, Deutsch D (1963). "Attention: Some theoretical considerations". Psychological Review; 70(1): 80-90.

21. Dijksterhuis A, Aarts H, Smith P K (2005). "The power of the subliminal: On subliminal persuasion and other potential applications". In R R Hassin, J S Uleman, J A Bargh (Eds.), Oxford series in social cognition and social neuroscience. The new unconscious (p. 77-106). Oxford University Press.

22. Duncan J (1980). "The locus of interference in the perception of simultaneous stimuli". Psychological Review; 87(3): 272-300.

23. Feinstein J S et al. (2010). "Bilateral limbic system destruction in man". Journal of Clinical and Experimental Neurophysiology; 32(1): 88-106.

24. Fiset P, Paus T, Daloze T, and others (1999). "Brain mechanisms of propofol-induced loss of consciousness in humans: A positron emission tomographic study". The Journal of Neuroscience; July, 1999, 19(13): 5506-5513.

25. Freud S (1999). The Standard Edition of the Complete Psychological Works of Sigmund Freud. (Editor and translator: James S), Vintage.

26. Gazzaniga M S (2005). "Forty-five years of split-brain research and still going strong". Nature Reviews/Neuroscience; August, 2005, 6: 653-659.

27. Ganong W F (2019). Ganong's Review of Medical Physiology. 26th ed.; Editors: Barrett K E, Barman S M, Brooks H L, Yuan J; 2019. McGraw-Hill Education. 
28. Greenwald A G, Klinger M R, Schuh E S (1995). “Activation by marginally perceptible ("subliminal") stimuli: dissociation of unconscious from conscious cognition". Journal of Experimental Psychology: General; 1995 Mar; 124(1): 22-42.

29. Harris C R, Coburn N, Rohrer D, Pashler H (2013). "Two Failures to Replicate HighPerformance-Goal Priming Effects”. PLoS ONE; 2003 Aug, 8(8): e72467.

30. Hillis A E, Newhart M, Heidler J, and others (2005). "Anatomy of Spatial Attention: Insights from Perfusion Imaging and Hemispatial Neglect in Acute Stroke". The Journal of Neuroscience; 2005, 25(12): 3161-3167.

31. Holender D (1986). "Semantic activation without conscious identification in dichotic listening, parafoveal vision, and visual masking: A survey and appraisal". The Behavioral and Brain Sciences; 1986, 9: 1-66.

32. Horga G, Maia T V (2012). "Conscious and unconscious processes in cognitive control: a theoretical perspective and a novel empirical approach". Frontiers in Human Neuroscience; 2012 Jul, 6: 199.

33. Huang Z, Tarnal V, Vlisides P E, et. al. (2021). "Anterior Insula regulates brain network transactions that gate conscious access". Cellreports 35, 109081, May 4, 2021.

34. Janet Pierre (1889). L'Automatisme Psychologique. 1889, Paris: Félix Alcan.

35. Karussis D, Leker R R, Abramsky O (2000). "Cognitive dysfunction following thalamic stroke: a study of 16 cases and review of the literature". Journal of the Neurological Sciences; 2000, 172: 25-29.

36. Kinney H C, Korein J, Panigrahy A, and others (1994). "Neuropathological findings in the brain of Karen Ann Quinlan: The Role of the Thalamus in the Persistent Vegetative State". The New England Journal of Medicine; May 26, 1994, 330(21): 1469-1475.

37. Koshi R (2018). Cunningham's Manual of Practical Anatomy. Volume 3, $16^{\text {th }}$ Edition, 2018; UK: Oxford University Press.

38. Lanciego J L, Luquin N, Obeso J A (2012). "Functional Neuroanatomy of the Basal Ganglia”. Cold Spring Harb Perspect Med; 2012, 2: a009621.

39. Langsjo J W, Alkire M T, Kaskinoro K, and others (2012). "Returning from Oblivion: Imaging the Neural Core of Consciousness". The Journal of Neuroscience; April, 2012, 32(14): 4935-4943.

40. Leibovitch F S, Black S E, Caldwell C B, and others (1998). "Brain-behavior correlations in hemispatial neglect using CT and SPECT: the Sunnybrook Stroke Study". Neurology; 1998, 50(4): 901-908.

41. Lewicki P, Hill T, Czyzewska M (1992). "Nonconscious acquisition of information". Review Article, American Journal of Psychology; Jun 1992, 47(6): 796-801. 
42. List A, Brooks J, Esterman M, and others (2008). "Visual hemispatial neglect, reassessed”. Journal of the International Neuropsychological Society; 2008, 14: 243-256.

43. Lull N, Noe E, Lull J J, and others (). "Voxel-based statistical analysis of thalamic glucose metabolism in traumatic brain injury: Relationship with consciousness and cognition". Brain Injury; 2010, 24(9): 1098-1107.

44. Lutkenhoff E S, Chiang J, Tshibanda L and others (2015). "Thalamic and Extrathalamic Mechanisms of Consciousness after Severe Brain Injury". Annals of Neurology; July, 2015, 78: $68-76$.

45. Moe H K, Moen K G, Skandsen T, and others (2018). "The Influence of Traumatic Axonal Injury in Thalamus and Brainstem on Level of Consciousness at Scene or Admission: A Clinical Magnetic Resonance Imaging Study”. Journal of Neurotrauma; April, 2018, 35: 975 984.

46. Moray N (1959). "Attention in dichotic listening: Affective cues and the influence of instructions". The quarterly journal of experimental psychology; Feb, 1959, 11(1): 56-60.

47. Packard M G, Knowlton B J (2002). "Learning and Memory Functions of the Basal Ganglia”. Annual Review of Neuroscience; 2002, 25: 563-593.

48. Pierson L, Trout M (2017). "What is Consciousness For?”. New Ideas in Psychology; 47(2017): 62-71.

49. Pinto Y, Neville D A, Otten M, and Others (2017). "Split Brain: divided perception but undivided consciousness". Brain; 2017, 140: 1231-1237.

50. Renzi E D, Gentilini M, Barbieri C (1989). "Auditory neglect". Journal of Neurology, Neurosurgery, and Psychiatry; 1989, 52: 613-617.

51. Schneider W, Fisk A D (1982). "Degree of consistent training: Improvements in search performance and automatic process development". Perception and Psychophysics; 31, 160168.

52. Shanks D R, Newell B R, Lee E H, Balakrishnan D, Ekelund L, et al. (2013). "Priming Intelligent Behavior: An Elusive Phenomenon". PLoS ONE; 8(4): e56515.

53. Shiffrin R M, Dumais S T (1981). "The development of automatism". In J R Anderson (Ed.), Cognitive skills and their acquisition; 111-140. Hillsdale, NJ: Erlbaum.

54. Squire L R, Adam J O (2015). "Conscious and Unconscious Memory Systems". Cold Spring Harbour Perspectives in Biology”; 7(3): a021667.

55. Strahan E J, Spencer S J, Zanna M P (2002). "Subliminal priming and persuasion: Striking while the iron is hot”. Journal of Experimental Social Psychology; 38(2002): 556-568. 
56. Swami Sarvapriyananda (2012). Bhagavad Gita for Students. YouTube: https://youtu.be/_EqwlOeTj7Y.

57. Underwood G (1976). "Semantic interference from unattended printed words". British Journal of Psychology; 67(3): 327-338.

58. Verdon V, Schwartz S, Lovblad K O, and others (2010). "Neuroanatomy of hemispatial neglect and its functional components: a study using voxel-based lesion-symptom mapping". Brain; 2010, 133: 880-894.

59. Vivekananda S (1891-1902). The Complete works of Swami Vivekananda. $1^{\text {st }}$ Ed.; Vedanta Pr.

60. Weng L, Xie Q, Zhao L, and others (2017). "Abnormal structural connectivity between the basal ganglia, thalamus, and frontal cortex in patients with disorders of consciousness". Cortex; 2017, 90: 71-87.

61. Willows D M, MacKinnon G E (1973). "Selective reading: Attention to the "unattended" lines”. Canadian Journal of Psychology; 27(3): 292-304.

62. Xie G, Deschamps A, Backman S B, and others (2011). "Critical involvement of the thalamus and precuneus during restoration of consciousness with physostigmine in humans during propofol anaesthesia: a positron emission tomography study". British Journal of Anaesthesia; 106(4): 548-557.

63. Yeo S S, Chang P H, Jang S H (2013). "The ascending reticular activating system from pontine reticular formation to the thalamus in the human brain". Frontiers in Human Neuroscience; July, 2013, volume 7, article 416:1-5.

64. Zheng W, Tan X, Liu T, and others (2021). "Individualized Thalamic Parcellation Reveals Alterations in Shape and Microstructure of Thalamic Nuclei in Patients with Disorder of Consciousness". Cerebral Cortex Communications; April, 2021; 1-15. 